\title{
AGR-5/6/7 Experiment Monitoring and Simulation Progress
}

Binh T. Pham, James W. Sterbentz, Grant L. Hawkes, Dawn M. Scates, and Joe J. Palmer

\section{August 2019}
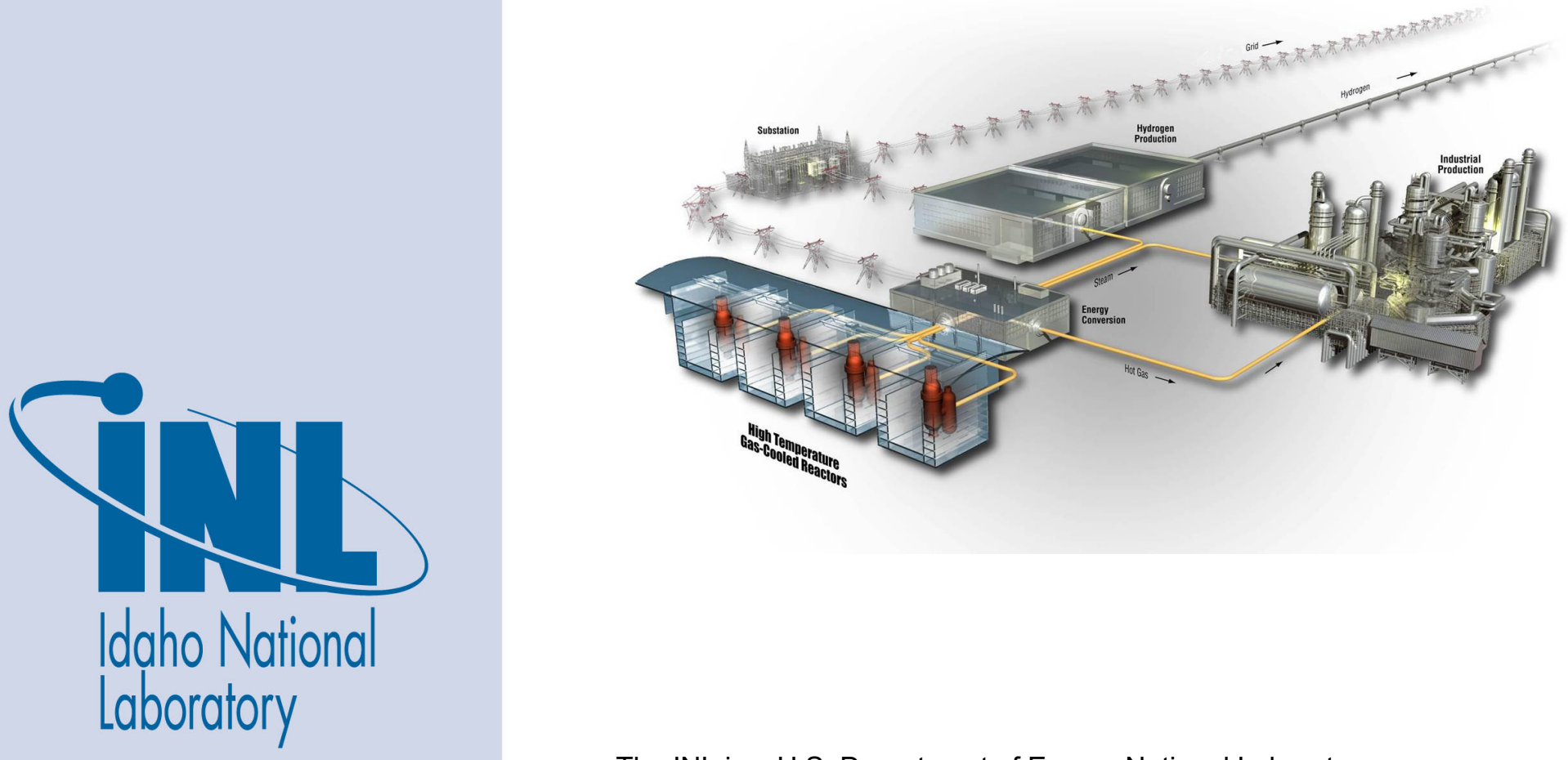

The INL is a U.S. Department of Energy National Laboratory operated by Battelle Energy Alliance 


\section{DISCLAIMER}

This information was prepared as an account of work sponsored by an agency of the U.S. Government. Neither the U.S. Government nor any agency thereof, nor any of their employees, makes any warranty, expressed or implied, or assumes any legal liability or responsibility for the accuracy, completeness, or usefulness, of any information, apparatus, product, or process disclosed, or represents that its use would not infringe privately owned rights. References herein to any specific commercial product, process, or service by trade name, trademark, manufacturer, or otherwise, does not necessarily constitute or imply its endorsement, recommendation, or favoring by the U.S. Government or any agency thereof. The views and opinions of authors expressed herein do not necessarily state or reflect those of the U.S. Government or any agency thereof. 
INL/EXT-19-55429

Revision 0

\title{
AGR-5/6/7 Experiment Monitoring and Simulation Progress
}

\author{
Binh T. Pham, James W. Sterbentz, \\ Grant L. Hawkes, Dawn M. Scates, and \\ Joe J. Palmer
}

August 2019

\begin{abstract}
Idaho National Laboratory INL ART Program Idaho Falls, Idaho 83415
\end{abstract}

http://www.inl.gov

Prepared for the

U.S. Department of Energy

Office of Nuclear Energy

Under DOE Idaho Operations Office

Contract DE-AC07-05ID14517 

INL ART Program

\section{AGR-5/6/7 Experiment Monitoring and Simulation Progress}

INL/EXT-19-55429

August 2019

Author:

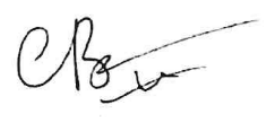

Binh T. Pham

$8 / 27 / 2019$

Date

Technical Reviewer: (Confirmation of mathematical accuracy; and correctness of data, and appropriateness of assumptions.)
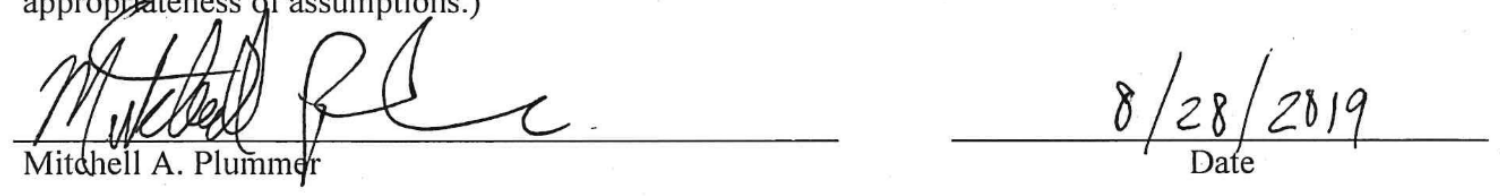

Approved by:
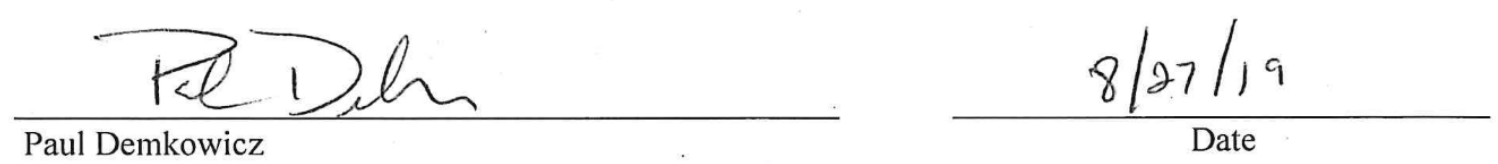

Paul Demkowicz

TRISO Fuel Director
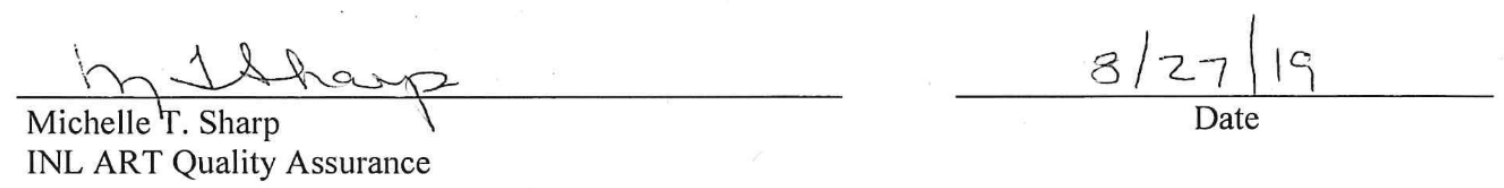


\section{ACKNOWLEDGEMENTS}

This work is supported by the DOE Advanced Reactor Technologies

Program at Idaho National Laboratory under the U.S. Department of Energy

Contract DE-AC07-05ID14517. 


\section{SUMMARY}

Advanced Gas Reactor (AGR)-5/6/7 is the last of a series of AGR experiments conducted in the Advanced Test Reactor (ATR) at Idaho National Laboratory (INL) in support of development and qualification of tri-structural isotropic (TRISO) low-enriched fuel for use in high-temperature gas-cooled reactors. The test train contains five separate capsules that are independently controlled and monitored. Each capsule contains multiple 12.51-mm-long compacts filled with low-enriched uranium carbide/oxide (UCO) TRISO fuel particles. The objectives of the AGR-5/6/7 experiment are to:

1. Irradiate reference-design fuel particles to support fuel qualification.

2. Establish operating margins for the fuel beyond normal operating conditions.

3. Provide irradiated-fuel performance data and irradiated-fuel samples for post-irradiation examination (PIE) and safety testing.

The primary objective of the AGR-5/6 test (Capsules 1,2, 4, and 5) is to verify successful performance of the reference-design fuel under normaloperating conditions. The AGR-7 test (Capsule 3) was designed to explore fuel performance at higher temperatures. Its primary objective is to demonstrate the capability of the fuel to withstand conditions beyond AGR-5/6 normal operating conditions in support of plant design and licensing. AGR 5/6/7 will also provide irradiated-fuel performance data on fission-gas release from failed particles during irradiation.

In order to achieve the test objectives, the AGR-5/6/7 experiment is being irradiated in the northeast flux trap of the ATR for an expected irradiation duration of 500 effective full-power days (EFPDs). The northeast flux trap was selected because its larger diameter provided greater flexibility for test-train design compared to the Large B positions used for the AGR-1 and AGR-2 irradiations, significantly enhancing capability for these combined irradiations. Irradiation began on February 16, 2018, and is expected to last 13 ATR cycles.

This document presents a current summary of the irradiation-monitoring and simulation data for the AGR 5/6/7 experiment. To date, the test has been irradiated for five complete cycles, resulting in approximately 174 EFPDs (about one-third of the 13-cycle schedule). However, calculated data are available only for the first four cycles, 162A-164B. At the end of 164B, burnup values on a percompact basis range from 2.50 to $7.81 \%$ fissions per initial heavy metal atom, while fast fluence values range from 0.73 to $2.31 \times 10^{25} \mathrm{n} / \mathrm{m}^{2}(\mathrm{E}>0.18 \mathrm{MeV})$. Time-averaged volume-averaged fuel temperatures on a capsule basis at the end of Cycle 164B ranged from $705^{\circ} \mathrm{C}$ in Capsule 5 to $1381^{\circ} \mathrm{C}$ in Capsule 3. Fissiongas release-rate-to-birth-rate $(\mathrm{R} / \mathrm{B})$ ratios are in the $10^{-8}-10^{-6}$ range. 


\section{CONTENTS}

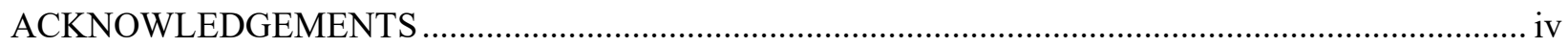

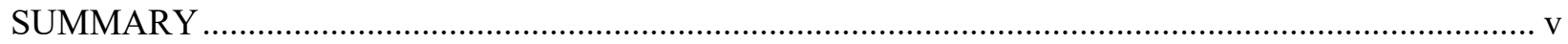

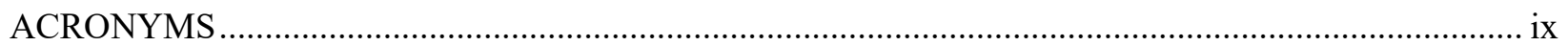

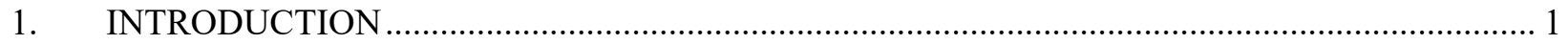

2. ADVANCED GAS REACTOR-5/6/7 IRRADIATION EXPERIMENT DESIGN......................... 2

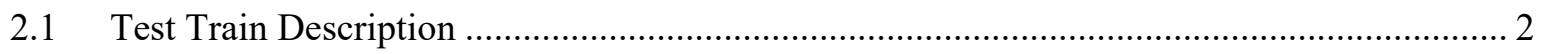

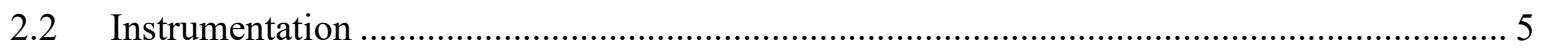

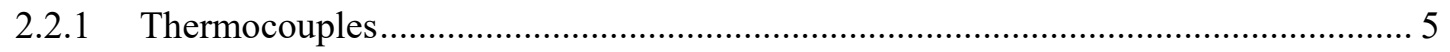

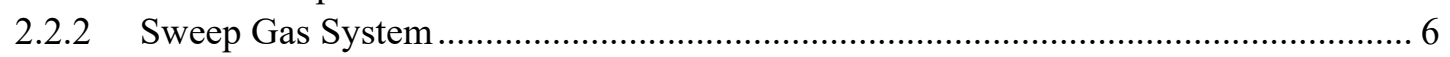

2.2.3 Fission Product Monitoring System ................................................................... 7

3. SIMULATION AND CALCULATION METHODOLOGIES …............................................ 9

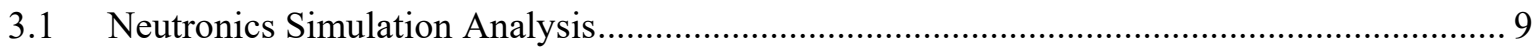

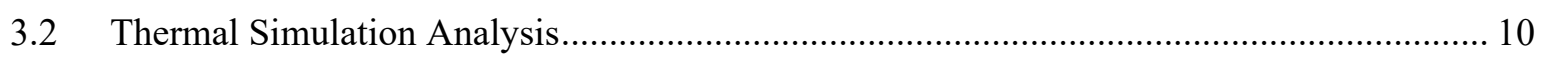

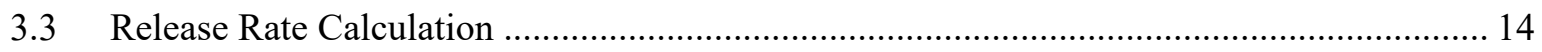

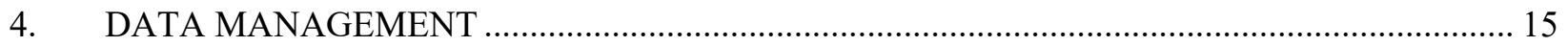

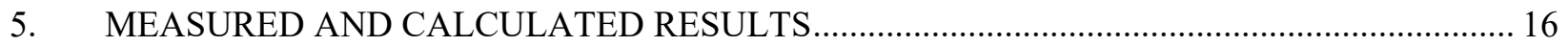

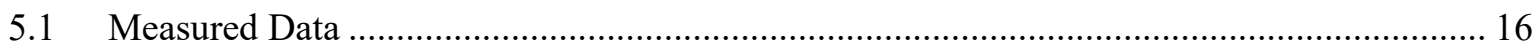

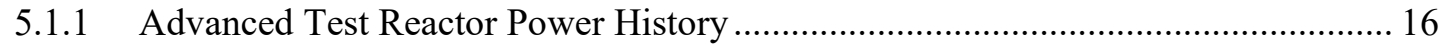

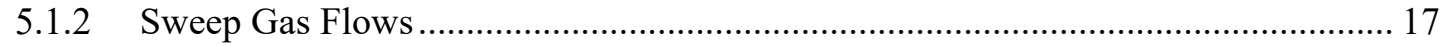

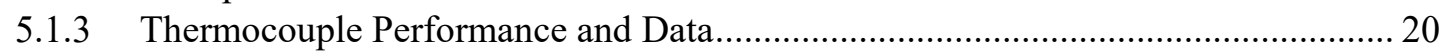

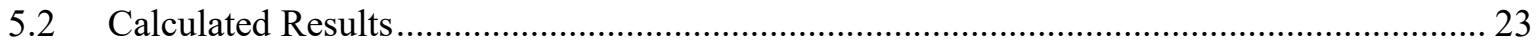

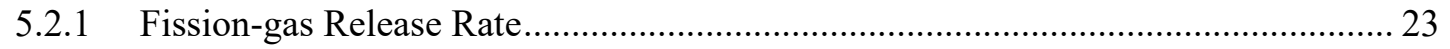

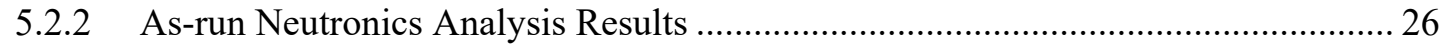

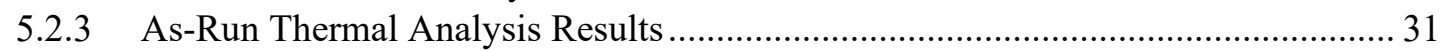

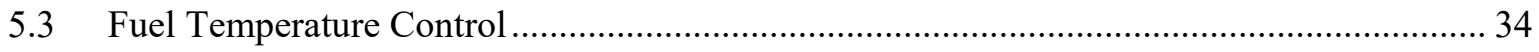

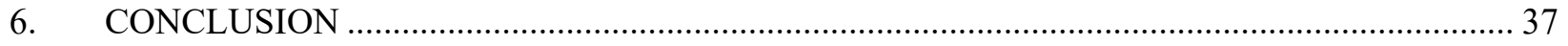

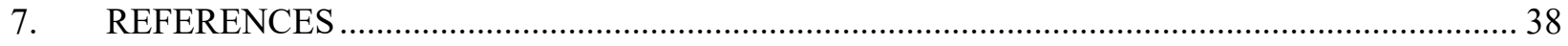

APPENDIX A Compact Time-averaged Temperature, Burnup, and Fast neutron Fluence at the End of 164B

\section{FIGURES}

Figure 1. ATR core cross-section displaying the NEFT position. .........................................................2

Figure 2. Schematic view of the AGR-5/6/7 test train (Note: Capsule 5 is at the top of the test train)........ 3

Figure 3. Cross-sections of the AGR 5/6/7 capsules showing the compact stacks (Top: Capsule 1

[left] and Capsules 2, 4, and 5 [right]; Bottom: Capsule 3).................................................... 4

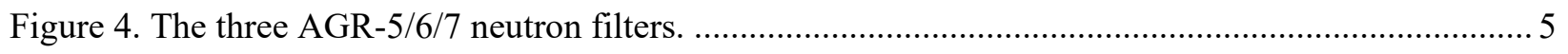

Figure 5. Simplified flow path for AGR-5/6/7 sweep gas. ............................................................. 7 
Figure 6. Gross-radiation monitor and spectrometer detector for one AGR-5/6/7 sweep gas line.............. 8

Figure 7. Cut-away view of finite element mesh of entire capsule train. .............................................. 10

Figure 8. Straight on top-down view temperature contours of the Capsule 1 graphite holder and fuel compacts at axial mid-plane. Left is capsule centered; right is capsule offset $0.0254 \mathrm{~mm}$ in southwest direction.

Figure 9. Cut-away view of temperature distribution of entire capsule train. ......................................... 12

Figure 10. Difference between measured and calculated TC temperatures versus EFPD........................ 13

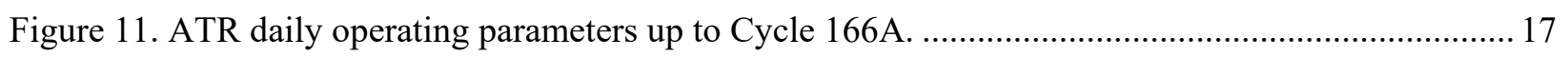

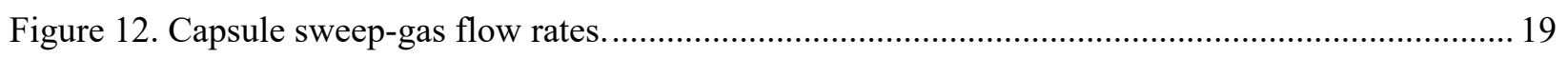

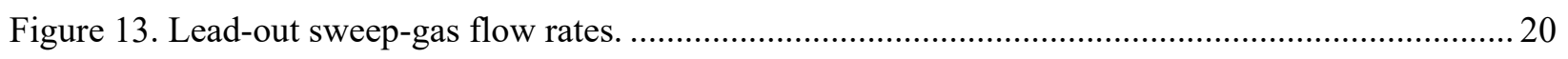

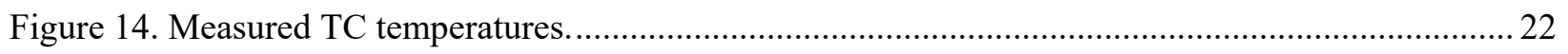

Figure 15. Measured R/B in AGR-5/6/7 capsules for krypton isotopes. ............................................... 24

Figure 16. Measured R/B in AGR-5/6/7 capsules for xenon isotopes.................................................. 25

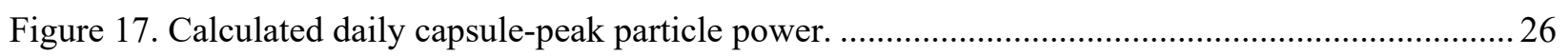

Figure 18. Calculated daily minimum, maximum, and volume-averaged compact power density............28

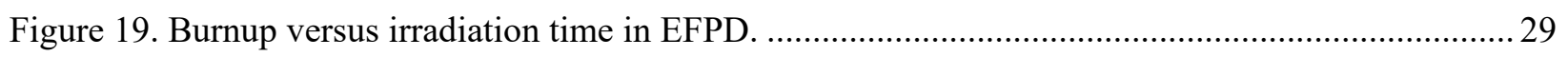

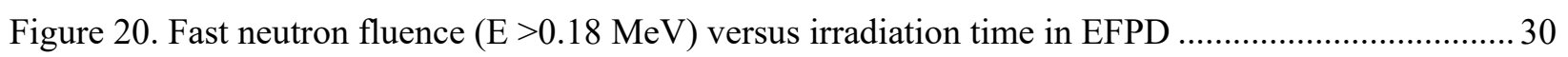

Figure 21. Calculated daily minimum, maximum, and volume-averaged fuel temperatures. .....................32

Figure 22. Calculated time-averaged minimum, time-averaged maximum, and time-averaged volume-

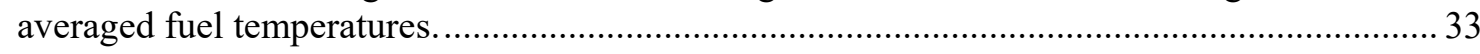

Figure 23. Time-averaged fuel temperature fraction by range for AGR-5/6 capsules (only days when control TC reached setpoint temperature are included in the time averaging).......................... 35

Figure 24. Time-averaged fuel-temperature fraction by range for AGR-7 capsule (only days when control TC reached setpoint temperature are included in the time averaging)..........................36

\section{TABLES}

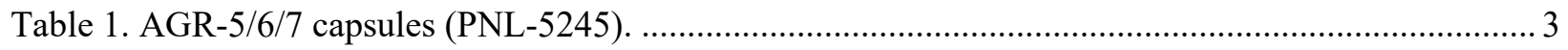

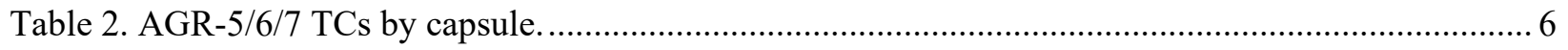

Table 3. Completed ATR cycles for AGR-5/6/7 irradiation to date...................................................... 16

Table 4. TC failures in AGR-5/6/7 capsules by the end of ATR Cycle 165A (38 failed out of 54).......... 21

Table 5. AGR-5/6/7 measured R/B and uncertainty statistics for selected krypton and xenon isotopes.... 23

Table 6. Minimum, average, and peak compact burnup and fast fluence at the end of 164B ..................2 27

Table 7. Compact temperature per capsule and experiment at the end of 164B .................................... 31

Table 8. Time-averaged temperature at the end of 164B (Note: fuel distribution calculation excludes extreme low-temperature periods at the beginning of the first cycle 162B and the PALM

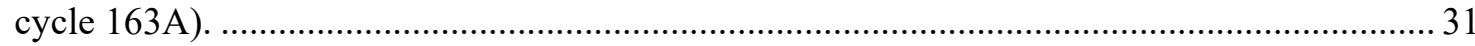

Table 9. Compact time-averaged temperature, burnup, and fast neutron fluence at the end of 164B....... 41 


\section{ACRONYMS}

AGR Advanced Gas Reactor

ART Advanced Reactor Technologies

ATR Advanced Test Reactor

ECAR engineering calculation and analysis report

EFPD effective full-power day

FPMS Fission Production Monitoring System

HTGR high-temperature gas-cooled reactor

INL Idaho National Laboratory

MCNP Monte Carlo n-Particle (code)

NDMAS Nuclear Data Management and Analysis System

NEFT northeast flux trap

PALM powered axial locator mechanism

PIE post-irradiation examination

$\mathrm{R} / \mathrm{B} \quad$ release-to-birth ratio

TC thermocouple

TRISO tri-structural isotropic

U.S. United States

UCO uranium carbide/oxide 


\section{AGR-5/6/7 Experiment Monitoring and Simulation Progress}

\section{INTRODUCTION}

AGR-5/6/7 is the last of a series of Advanced Gas Reactor (AGR) experiments sponsored by Advanced Reactor Technologies (ART) and conducted in the Advanced Test Reactor (ATR) at Idaho National Laboratory (INL) in support of development and qualification of tri-structural isotropic (TRISO) low-enriched fuel for use in a high-temperature gas-cooled reactor (HTGR). The configuration and irradiation conditions of the AGR experiments are based on prismatic HTGR technology, a technology involving the use of helium coolant, a low-power-density ceramic core capable of withstanding very high temperatures, and coated-particle fuel (PLN-3636 2018). The objectives of the AGR-5/6/7 experiment are to (PNL-5245 2018):

1. Irradiate reference-design fuel containing low-enriched uranium carbide/oxide (UCO) TRISO fuel particles to support fuel qualification.

2. Establish operating margins for the fuel beyond normal operating conditions.

3. Provide irradiated fuel performance data and irradiated fuel samples for post-irradiation examination (PIE) and safety testing.

The primary objective of the AGR-5/6 test is to verify successful performance of the reference-design fuel by demonstrating compliance with statistical-performance requirements under normal-operating conditions. The AGR-7 test was designed to explore fuel performance at higher fuel temperatures. Its primary objective is to demonstrate the capability of the fuel to withstand conditions beyond AGR-5/6 normal-operating conditions in support of plant design and licensing.

AGR-5/6/7 will also provide irradiated-fuel performance data on the release of fission-gas from failed particles during irradiation. The in-pile gas release, PIE, and safety-testing data on fission-gas and metal release from kernels will be used in the development of improved models of fuel performance and fissionproduct transport.

This document presents irradiation-monitoring and simulation progress of the AGR-5/6/7 experiment. To date, the AGR-5/6/7 fuel test has been irradiated for five completed cycles, resulting in approximately 174 effective full-power days (EFPDs, about one-third of the 13-cycle schedule). Monitoring data include sweep-gas flow rates, thermocouple (TC)-measured temperatures, and fission-gas release rates.

Simulation data include burnup, fast neutron fluence, fission heat rates, fission-gas birthrates (results from neutronics analysis), and temperatures (results from thermal analysis) for fuel compacts and components. Fission-gas release-rate-to-birth-rate $(\mathrm{R} / \mathrm{B})$ ratios, calculated from the measured release rates and calculated birthrates for twelve isotopes (Kr-85m, Kr-87, Kr-88, Kr-89, Kr-90, Xe-131m, Xe-133, $\mathrm{Xe}-135, \mathrm{Xe}-135 \mathrm{~m}, \mathrm{Xe}-137, \mathrm{Xe}-138$, and Xe-139) are also included. Performance of the 54 installed TCs and issues with the sweep-gas system are also discussed. 


\section{ADVANCED GAS REACTOR-5/6/7 IRRADIATION EXPERIMENT DESIGN}

To achieve the test objectives outlined above, AGR-5/6/7 is being irradiated in the northeast flux trap (NEFT) position of the ATR at INL. A core cross-section indicating this location is displayed in Figure 1. The NEFT provides greater flexibility for test train design compared to the Large B positions used for the AGR-1 and AGR-2 irradiations, significantly enhancing the capability for the combined irradiations (PLN-5245, “AGR-5-6-7 Irradiation Experiment Test Plan"). Advantages of the NEFT position include that it:

- Efficiently utilizes the ample space afforded by the NEFT to accommodate enough fuel for the needs of qualification and margin tests

- Reduces irradiation time required by taking advantage of the higher flux levels relative to other ATR irradiation locations

- Allows the use of neutron filters to maintain more consistent compact power as the fuel burns out

- Allows power-level control (corner lobes are controlled independently).

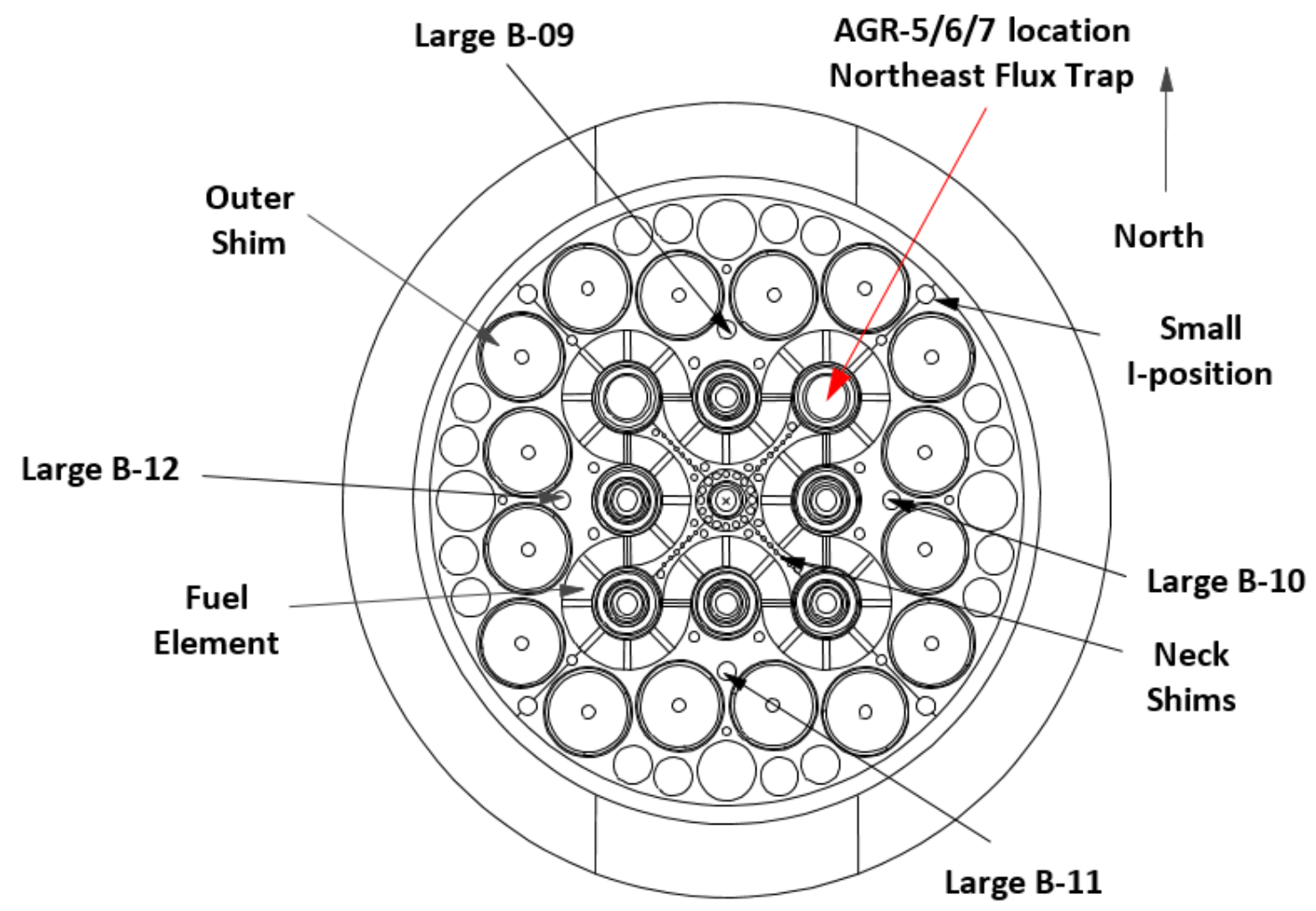

Figure 1. ATR core cross-section displaying the NEFT position.

\subsection{Test Train Description}

The experimental test train consists of five independently controlled and monitored capsules stacked on top of each other, as shown in Figure 2. Capsules 1, 2, 4, and 5 comprise the AGR-5/6 experiment while Capsule 3 is the AGR-7 experiment. 


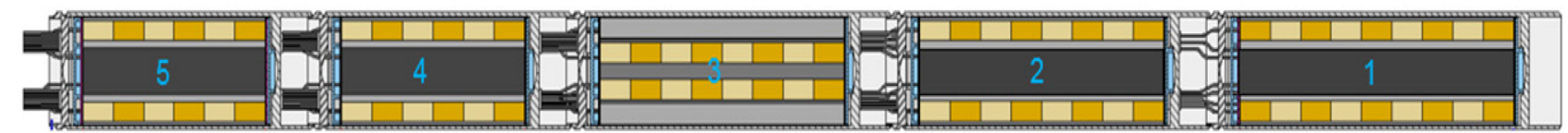

Figure 2. Schematic view of the AGR-5/6/7 test train (Note: Capsule 5 is at the top of the test train).

The five separate capsules use the full 1.2-m active core height in ATR to maximize the amount of irradiated fuel ( 515,000 particles in AGR-5/6 and 55,000 particles in AGR-7) and span the broad range of fuel-burnup and temperature combinations expected in a modular HTGR. To achieve test goals and still be able to control the temperature in the capsules, compacts with two different packing fractions of particles were included in the test train. Packing fraction is defined as the total volume of particles divided by the total volume of the compact; Capsules 1 and 5 contain compacts with a $40 \%$ nominal packing fraction, and Capsules 2, 3, and 4 contain compacts with a $25 \%$ nominal packing fraction. Capsule 1 contains the greatest number of compacts (90). Capsules 3, 4, and 5 each contain 24 compacts; and Capsule 2 contains 32 compacts (Table 1).

Table 1. AGR-5/6/7 capsules (PNL-5245).

\begin{tabular}{|c|c|c|c|c|c|}
\hline \multirow[b]{2}{*}{ Capsule } & \multicolumn{3}{|c|}{ Numbers of } & \multirow{2}{*}{$\begin{array}{l}\text { Average Packing } \\
\text { Fraction (\%) }\end{array}$} & \multirow{2}{*}{$\begin{array}{c}\text { Approximate Number } \\
\text { of Particles (b) }\end{array}$} \\
\hline & Levels & Stacks & Compacts & & \\
\hline 5 & 6 & 4 & 24 & 38.4 & $3393^{(\mathrm{c})}$ \\
\hline 4 & 6 & 4 & 24 & 24.9 & $2197^{(\mathrm{c})}$ \\
\hline 3 & 8 & 3 & 24 & 25.5 & $2265^{(\mathrm{c})}$ \\
\hline 2 & 8 & 4 & 32 & 25.5 & $2264^{\text {(c) }}$ \\
\hline 1 & 9 & 10 & 90 & 38.4 & $3434^{\text {(c) }}$ \\
\hline $\begin{array}{c}\text { AGR-5/6 } \\
\text { AGR-7 } \\
\text { Total }\end{array}$ & - & - & $\begin{array}{c}170 \\
24 \\
194\end{array}$ & - & $\begin{array}{c}515,668 \\
54,360 \\
570,028\end{array}$ \\
\hline $\begin{array}{ll}\text { (a) } & \text { Average } \\
\text { (b) Number } \\
\text { (c) Number }\end{array}$ & $\begin{array}{l}\text { king fracti } \\
\text { articles ob } \\
\text { articles pe }\end{array}$ & $\begin{array}{l}\text { r each con } \\
\text { d by divid } \\
\text { npact }\end{array}$ & $\begin{array}{l}\text { lot } \\
\text { ranium mas }\end{array}$ & a compact by uranit & ss content of a particle. \\
\hline
\end{tabular}

In each AGR-5/6 capsule, the fuel stacks are contained in a graphite holder, separated from the capsule shell by a gas gap (top capsules in Figure 3). AGR-7 Capsule 3 has two gas gaps because fuel stacks are contained in the inner graphite holder, which is separated from the outer graphite holder by an inner gas gap (bottom capsule in Figure 3). These temperature-control gas gaps have axially varying width to compensate for the axial variation in heating. The temperature of the graphite holder is monitored by TCs to ensure the fuel is operating at the expected irradiation temperatures. Each capsule contains an individual gas line to separately provide the helium-neon gas mixture used in the control gas gap to adjust the temperature in the capsule based on TC readings. The capsules are welded together to form the core section of the test train. The plenum regions between capsules have been extended over previous AGR designs to accommodate the bending of larger and stiffer TCs. The core section is welded to a lead-out tube that houses and protects the gas lines and TC leads. The lead-out is routed from the NEFT position straight up from the ATR core to the experiment penetration in the reactor vessel top head. Above the vessel top head, the gas lines and TC leads are connected to their facility counterparts in the temperature-monitoring, control, and data-collection systems. 
To shape the temporal and spatial fuel power distribution, two techniques are used to adjust the neutron flux incident on the test train: placing a neutron filter around the capsules and raising the northeast lobe power throughout irradiation as the test fuel is depleted. The neutron filters consist of inner and outer stainless-steel shells with a natural hafnium-metal foil filter sandwiched between them (Figure 4). The hafnium foil in the filters efficiently absorbs thermal neutrons, which in turn significantly decrease compact fission and power densities to control temperature and burnup. Three different filters (shrouds) were originally designed for use during irradiation: a heavy filter (hafnium foil sandwiched between stainless-steel tubes), an intermediate filter (partial tube of hafnium foil sandwiched between stainless-steel tubes), and a light filter (stainless-steel tube). The hafnium foil is centered axially about the ATR core mid-plane and extends $50.8 \mathrm{~cm}$ above and below the core mid-plane for a total axial length of $101.6 \mathrm{~cm}$. The axial extent of the hafnium does not fully cover the top of Capsule 5 or the bottom of Capsule 1 to increase the compact power densities and burnup in these regions. As a result, the compact power densities can remain relatively constant and uniform for the northeast-lobe power variations during irradiation.

\section{Capsule 1}

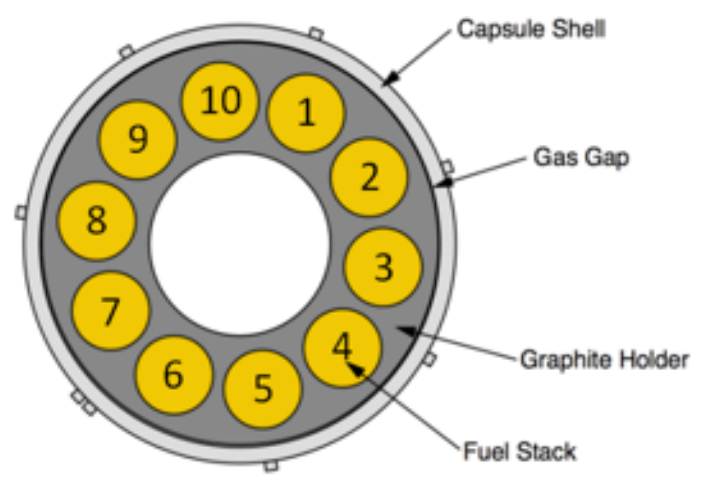

\section{Capsule 2, 4, 5}

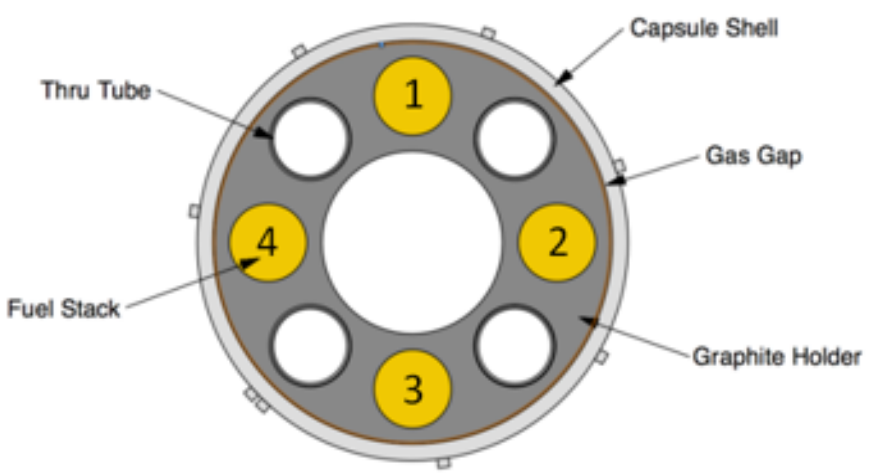

\section{Capsule 3}

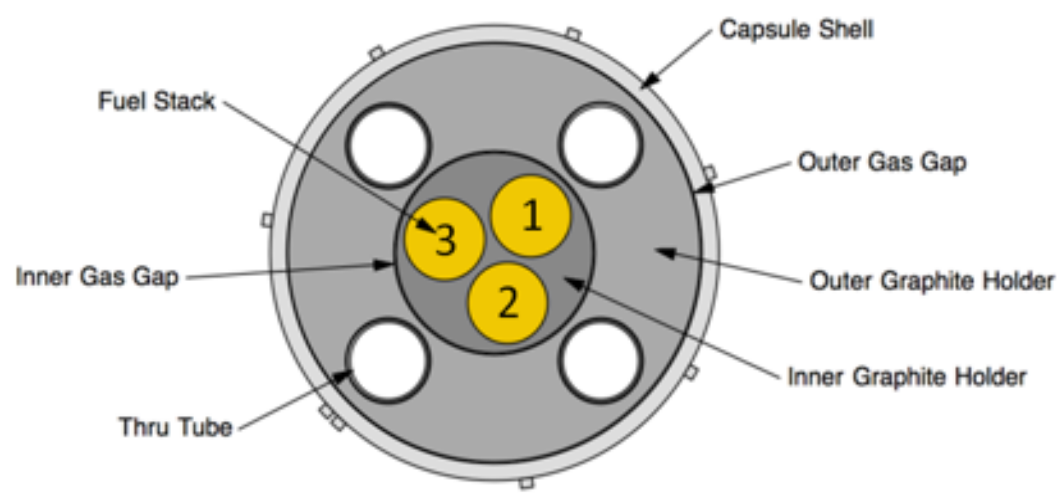

Figure 3. Cross-sections of the AGR 5/6/7 capsules showing the compact stacks (Top: Capsule 1 [left] and Capsules 2, 4, and 5 [right]; Bottom: Capsule 3). 


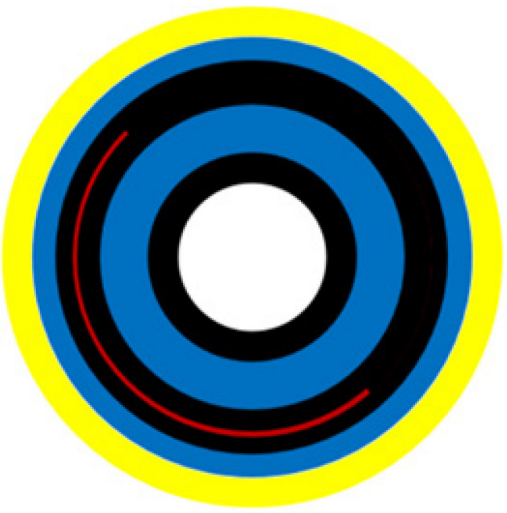

Filter 2

SS-Hf-SS

$180^{\circ} 0.18-\mathrm{mm} \mathrm{Hf}$

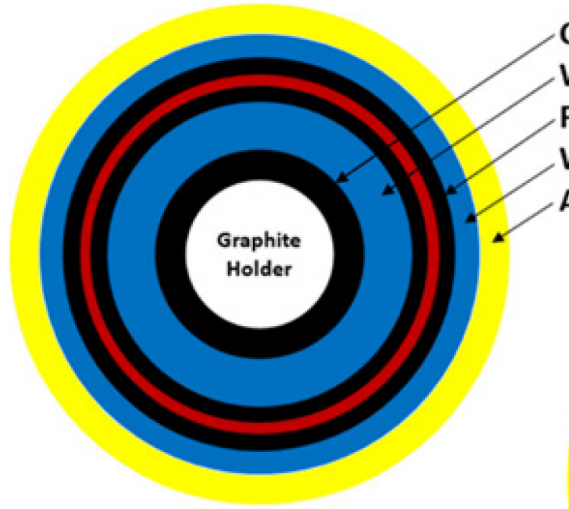

Filter 1

SS-Hf-SS

$360^{\circ} 0.53-\mathrm{mm} \mathrm{Hf}$

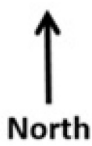

Capsule wall

Water

Filter (Stainless Steel / Hafnium)

Water

Al baffle

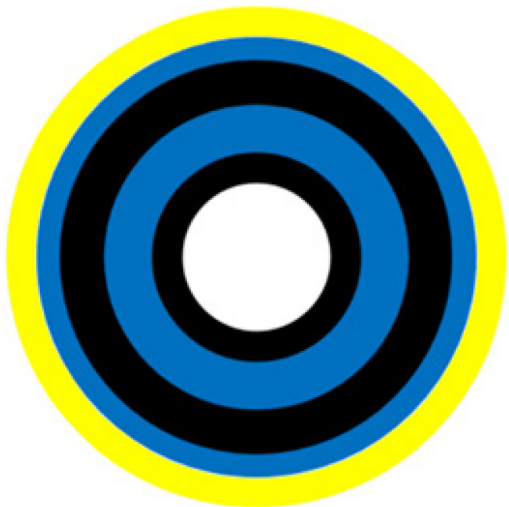

Filter 3

SS-SS-SS

Figure 4. The three AGR-5/6/7 neutron filters.

\subsection{Instrumentation}

\subsubsection{Thermocouples}

The number of TCs installed in the AGR-5/6/7 capsules was substantially increased, relative to previous experiments, based on the high failure rate among TCs previously experienced. Seventeen TCs were installed in the highest-temperature capsules (i.e., 1 and 3) to maximize the likelihood that at least one TC would survive the entire irradiation campaign. This is essential for independent temperature control in the capsules. The four types of TCs used in the capsules are

- Type $\mathrm{N}$ (Ni/Cr/Si/Mg wire), with Inconel 600 (Ni/Cr/Fe/Mn alloy) sheath, MgO insulation, and sleeved with $\mathrm{Nb}$ (standard baseline).

- Type $\mathrm{N}$, with Cambridge low-drift pure $\mathrm{Ni}$ sheath, $\mathrm{MgO}$ insulation, and sleeved with $\mathrm{Nb}$ in the AGR-5/6 capsules and with $\mathrm{ZrO}_{2}$ in AGR-7 Capsule 3.

- Type $\mathrm{N}$, with Inconel 600 sheath, Spinel $\left(\mathrm{MgAl}_{2} \mathrm{O}_{4}\right)$ insulation, and sleeved with $\mathrm{Nb}$.

- High-temperature irradiation resistant (HTIR, $\mathrm{Mo} / \mathrm{Nb}$ wire), with $\mathrm{Nb}$ sheath, $\mathrm{Al}_{2} \mathrm{O}_{3}$ insulation, and sleeved with Mo.

The selection of these TCs relied on the established performance of commercial TCs and on feedback from prior AGR experiments. Among commercial TCs, standard base metal TCs (Types K and N) decalibrate (drift) at high temperatures due to metallurgical changes $\left(>600^{\circ} \mathrm{C}\right.$ for Type $\mathrm{K}$ and $>1000^{\circ} \mathrm{C}$ for Type N). Based on AGR-1 experience, Type N TCs were deemed appropriate and selected for the low-temperature capsules (2, 4, and 5 as shown in Table 2). For the high-temperature capsules (1 and 3), the Spinel, Cambridge, and HTIR TCs were used in locations expected to experience temperatures above $1200^{\circ} \mathrm{C}$ (Table 2). A summary of TC type and placement within the test train is provided in Table 10 of the AGR-5/6/7 irradiation experiment test plan (PLN-5245). 
Table 2. AGR-5/6/7 TCs by capsule.

\begin{tabular}{|c|c|c|c|}
\hline Capsule & Installed TCs & TC Type (\# TCs) & TC Temperature Range $\left({ }^{\circ} \mathbf{C}\right)$ \\
\hline 1 (bottom) & 17 & $\begin{array}{c}\text { Spinel (1) } \\
\text { HTIR (9) } \\
\text { Cambridge (7) }\end{array}$ & $780-1400$ \\
\hline 2 & 8 & Type N (8) & $740-900$ \\
\hline 3 & 17 & $\begin{array}{c}\text { Spinel (4) } \\
\text { HTIR (6) } \\
\text { Cambridge (7) }\end{array}$ & $680-1500$ \\
\hline 4 & 6 & Type N (6) & $780-940$ \\
\hline 5 (top) & 6 & Type N (6) & $700-820$ \\
\hline
\end{tabular}

\subsubsection{Sweep Gas System}

Independent gas lines route a mixture of inert helium and neon gases through each of the five capsules to provide temperature control and to sweep released fission-product gases to the fission-product monitoring system (FPMS). Figure 5 shows a simplified flow path for the AGR-5/6/7 sweep gas from the mass-flow controller to the FPMS. Sweep-gas flow, originating from gas-supply bottles, is routed to the mass-flow controller cabinet, where the helium and neon gases (low-neutron-activation inert gases) are blended for each capsule. The blending of sweep gases is accomplished by a computerized mass-flow controller before the gas enters the test train, based on feedback from the control TC. The sweep gas is then routed to the capsule inlet isolation panel, which can be used to isolate inlet gas flow to each capsule independently during reactor outages or in the event of a failure. Upon exiting the capsule and test train, the gas flows through the outlet isolation panel to another panel containing a particulate filter, moisture detector, and three-way valve. The valve routes the gas either to the designated fission-product monitor or to the standby, backup fission-product monitor. Another three-way valve allows the gas to be routed to a manual grab-sample line for additional analysis, if needed. After passing through the FPMS, the gas lines combine into a common exhaust header that routes the gas through a silver-zeolite filter. The exhaust gas is finally routed to the ATR stack.

Helium and neon sweep gases have the following specifications:

- Purities of $\geq 99.99 \%$ by volume for each gas to limit the amount of contamination to the test articles and to limit the background activity

- New gas-bottle verification: thermal conductivity and moisture measurements are performed for both the helium- and neon-gas lines

- Moisture content of $<5 \mathrm{ppm} \mathrm{H}_{2} \mathrm{O}$, at a dew point of $-100 \pm 2.5^{\circ} \mathrm{C}$ within the sweep gas to reduce possible reactions with the graphite contained in the test capsule

- Gas flow of $\leq 50 \mathrm{sccm}$ at a pressure of about 7-21 kPa-gauge (or 1-3 psig).

To prevent capsule to capsule cross gas leakage, a nominal helium or neon flow of $1-5 \mathrm{sccm}$ per capsule at about $6.9 \mathrm{kPa}$-gauge (or $1 \mathrm{psig}$ ) above the capsule pressure will be provided via a mass-flow controller into the lead-out cavity, for a total flow of 5-20 sccm, which then flows into the common plenums between capsules. The through tubes end at the bottom of Capsule 2 . 


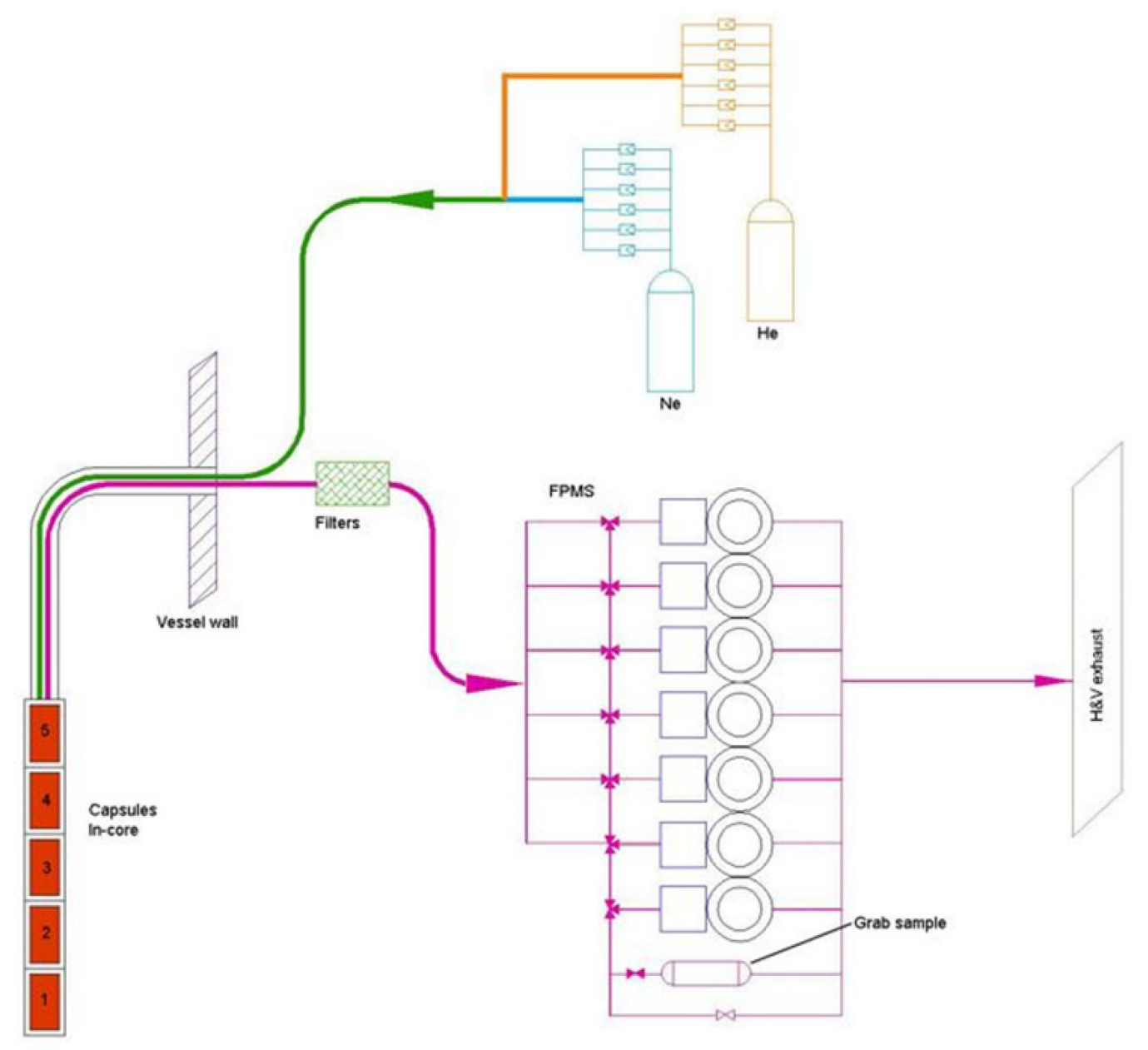

Figure 5. Simplified flow path for AGR-5/6/7 sweep gas.

\subsubsection{Fission Product Monitoring System}

Each AGR-5/6/7 capsule is continuously monitored for fission gas release by the fission-product monitoring system (FPMS). The FPMS consists of seven sets of gross-radiation monitor and spectrometer detector pairs. One detector set is designated for each of the five capsules, while the two remaining detector sets serve as spares. A detector set is illustrated in Figure 6. Under normal operation, computerized data acquisition, analysis, and storage occur continuously without operator intervention.

Sweep gas carries released fission-product gases from the capsules to the detector system under normal conditions with a transit time expected to be about 150 seconds. The sweep gas passes in front of the gross-radiation monitor, which uses a thallium-doped sodium iodide (NaI[Tl]) detector to detect each fuel-particle failure up to the first 250 failures.

Flow continues to the spectrometer system, which uses a high-purity germanium (HPGe) detector. The spectrometer detector systems measure the concentrations of various krypton and xenon isotopes in the sweep gas from each capsule. During normal operation, 8-hour counting intervals are used to measure the concentrations of Kr-85m, Kr-87, Kr-88, Kr-89, Kr-90, Xe-131m, Xe-133, Xe-135, Xe-135m, Xe137, Xe-138, and Xe-139. The select nuclides were chosen because they are chemically inert fissionproduct gases with relatively short half-lives, allowing each isotope to reach equilibrium concentration in the fuel during each reactor cycle. These measured concentrations are converted to per-capsule release rates for each isotope, which are automatically stored and backed up. 
During reactor outages, the capsules are swept with pure helium; the remaining effluent is analyzed for fission gas. Of particular interest are the fission gas concentrations of Xe-133, Xe-135, and $\mathrm{Xe}-135 \mathrm{~m}$, which are measured and recorded for at least 2 days following each reactor shutdown. These xenon concentrations are used to calculate concentrations of their parent iodine isotopes, which are an indication of fuel performance.

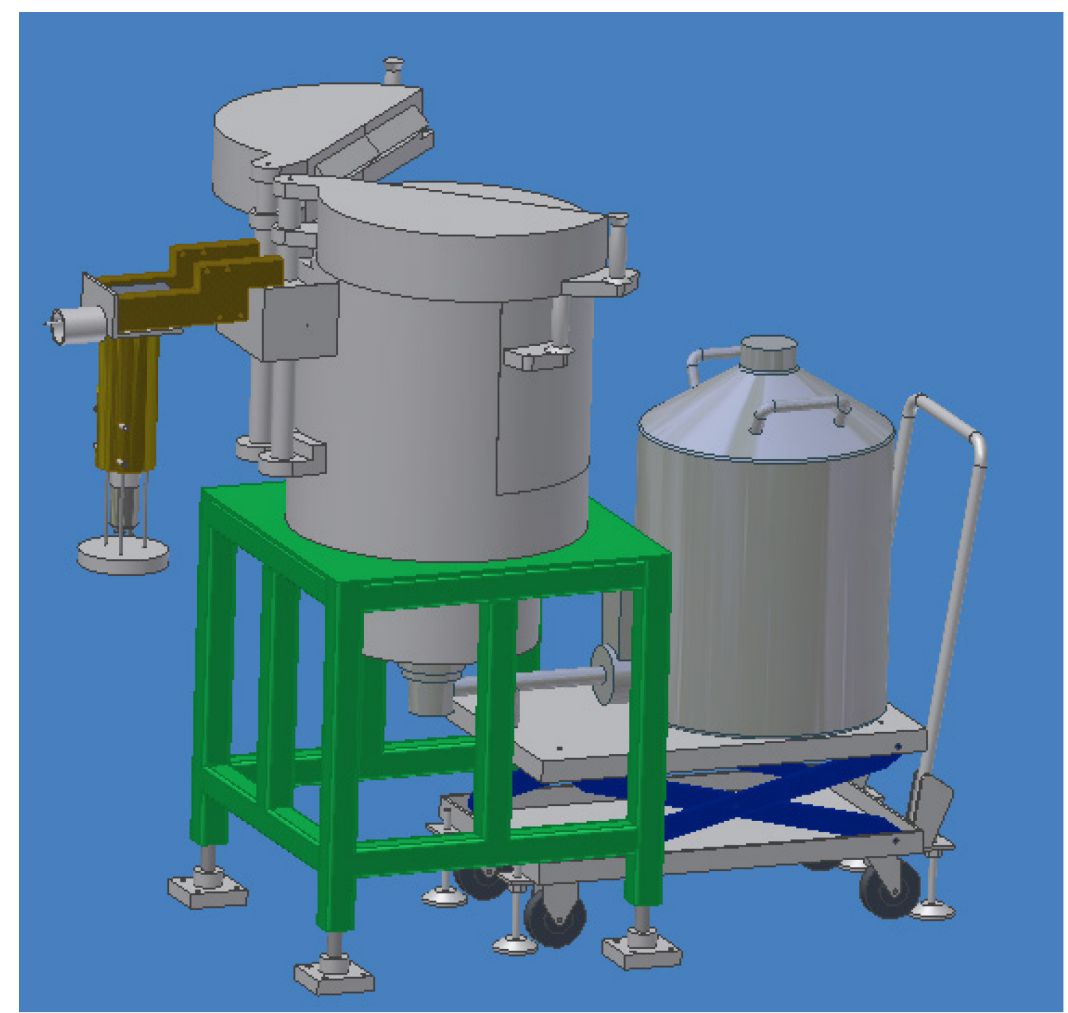

Figure 6. Gross-radiation monitor and spectrometer detector for one AGR-5/6/7 sweep gas line. 


\section{SIMULATION AND CALCULATION METHODOLOGIES}

Most of physical parameters describing irradiation conditions of the AGR test fuel are calculated using simulation models. They include fission-power density, fast neutron fluence, and burnup for fuel compacts, calculated from neutronics depletion code; fuel temperature, calculated based on thermalsimulation code; and fission-gas R/B, calculated based on the measured release rate per capsule and calculated birthrate. After completion of each cycle, an as-run neutronics analysis is performed using actual ATR operating parameters. The heating rate and fast fluence from neutronics analysis, combined with neon fraction in the gas flow to each capsule, are used in the thermal model to calculate daily fuelcompact temperature. During this time, the $\mathrm{R} / \mathrm{B}$ ratios are also calculated using fission-product-isotope birth rates, calculated by the neutronics code. Detailed model descriptions for the AGR-5/6/7 as-run fission-product release, thermal, and neutronics analyses will be reported in a separate engineering calculation and analysis report (ECARs) for each analysis. The following subsections provide a summary of each of simulation methodologies that are specific to the AGR-5/6/7 experimental design and irradiation conditions.

\subsection{Neutronics Simulation Analysis}

Neutronics analysis of the AGR-5/6/7 test train was performed using JMOCUP, a coupling code developed at INL that combines the continuous-energy Monte Carlo N-Particle (MCNP) transport code (LANL 2004) and the depletion code ORIGEN (Croff 1983). The JMOCUP depletion methodology was used to model and deplete the AGR-5/6/7 TRISO fuel compacts in the northeast flux trap of ATR, based on a hypothetical 13-cycle irradiation schedule. This AGR-5/6/7 depletion analysis was performed for use in the capsule, test-train, and filter-design iterations and final design activities. A detailed description of the JMOCUP system and verification and validation of the preliminary JMOCUP depletion calculation for AGR-5/6/7 experiment were documented in ECAR-2961 (Sterbentz 2017). The similarity in test-train design between AGR-3/4 and AGR-5/6/7, in conjunction with the similarity in reactivity worth of the two test-train configurations and the low worth of the fuel compacts, allowed the same JMOCUP Monte Carlo depletion methodology and software modules to be used in both the AGR-3/4 neutronics calculation (Sterbentz 2015) and the AGR-5/6/7 neutronics calculation.

The JMOCUP depletion calculation coordinated three depletions: (1) the ATR driver core, (2) the AGR-5/6/7 TRISO compacts, and (3) the AGR-5/6/7 hafnium capsule shroud (i.e., the thermal neutron filter). The ATR driver core consists of 840 depletion cells in the MCNP model, or three radial and seven axial cells per each of the 40 driver elements in the serpentine ATR core. The 194 AGR-5/6/7 fuel compacts were homogenized, and each was split into four axial segments for a total of 776 compact depletion cells. The hafnium shroud had 40 depletion cells, two azimuthal by 20 axial segments. Therefore, there were 1656 depletion cells in the MCNP full-core ATR model. JMOCUP depleted each cell at each time step. The ATR driver-fuel depletion cells each contain nine actinide isotopes and 24 fission-product isotopes, the concentrations of which, along with their fission and radiative-capture crosssections are tracked and updated at each time step. Similarly, the compacts have 21 tracked actinides and 71 tracked fission products. In the hafnium-shroud cells, the six naturally occurring hafnium isotopes are tracked. The MCNP code calculates cell flux and specified nuclear reaction rates for every isotope in each depletion cell at every time step. Using these data, updated isotopic concentrations and one-group cross sections are fed to the ORIGEN input files along with the cell-average neutron flux for the next ORIGEN depletion calculation.

The neutron transport problem in the JMOCUP method is solved using the KCODE option in the MCNP code. For the KCODE option to be effective, the ATR driver fuel must be simultaneously depleted along with the AGR-5/6/7 experiment depletions. Modeling the depletion of the entire ATR core provides realistic neutron and gamma sources for analyzing the AGR-5/6/7 experiment's radiation environment. The effects of important operational details (such as the positions of the outer shim control cylinders and neck shims) can be considered on a daily average basis using this methodology. The ATR 
operating parameters used in the depletion model include the total core power, lobe powers, rotational movement of the outer shim control cylinders, and withdrawal of neck shim rods. The AGR-5/6/7 compacts are solid cylinders composed of TRISO particles and a graphite binder matrix with selected fabrication data presented in PLN-5245. The TRISO particle compacts are homogenized in the MCNP full-core models. The specific results of the neutronics analyses include:

- Compact fission heat rates $\left(\mathrm{W} / \mathrm{cm}^{3}\right)$

- Compact burnup in percent fissions of initial metal atoms (\%FIMA)

- Compact fast neutron fluence $(\mathrm{E}>0.18 \mathrm{MeV})$

- Neutron/gamma heat rates $\left(\mathrm{W} / \mathrm{cm}^{3}\right)$ for the AGR-5/6/7 experiment structural components, ATR coolant, and neutron filter

- Compact actinide and fission-product concentrations at end-of-irradiation

- Birth rates of fission-gas isotopes per capsule (atoms/sec)

- End-of-cycle I-135 concentrations (no decay).

Verification that the calculation executed properly was done through both technical checkers and post-processing of calculated data. The as-run JMOCUP depletion calculation for AGR-5/6/7 experiment based on the actual ATR operating conditions will be documented in the form of an ECAR, as was done for the previous experiments. The ECAR can be used as a basis for the qualification of the neutronics data.

\subsection{Thermal Simulation Analysis}

The Abaqus finite-element stress and heat transfer code (Abaqus 2014) was used to perform the daily as-run thermal analysis for AGR-5/6/7 capsules (Hawkes et al. 2019). These calculations were performed using compact and capsule components' heat-generation rates and fast neutron fluence provided by the neutronics analysis (see Section 3.1) and with additional operational input for daily helium/neon gasmixture composition and flow rate. The entire AGR-5/6/7 test train was described by a finite-element mesh formed from approximately 1,200,000 hexahedral finite-element bricks (Figure 7). Each compact was discretized with $\sim 3,500$ of such brick elements.

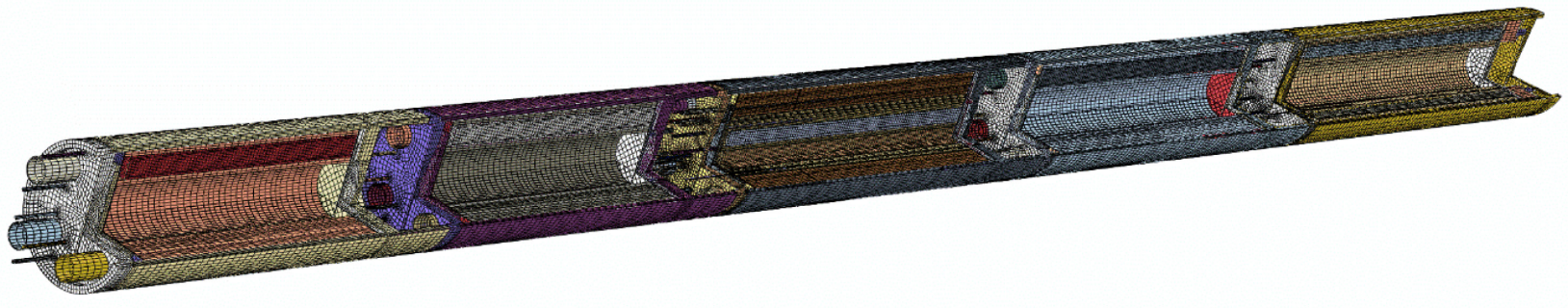

Figure 7. Cut-away view of finite element mesh of entire capsule train.

Fuel-compact thermal conductivity was taken from historical correlations that take into account temperature of heat treatment, irradiation temperature, fast neutron fluence, and the TRISO-particle packing fraction (Gontard and Nabielek 1990). In order to adjust for matrix density differences, the compact matrix thermal conductivity was scaled according to the ratio of the AGR-5/6/7 compact matrix density ( $1.75 \mathrm{~g} / \mathrm{cm}^{3}$ for Capsules $2-4$ and $1.73 \mathrm{~g} / \mathrm{cm}^{3}$ for Capsules 1 and 5) to the compact matrix density used to develop the correlations $\left(1.75 \mathrm{~g} / \mathrm{cm}^{3}\right)$. It was then combined with particle thermal conductivity obtained from Folsom et al. (2015), following an approach described by Gonzo (2002) to obtain an effective thermal conductivity for the compact at a given TRISO-particle volume-packing fraction. 
The AGR-5/6/7 graphite holders are made of IG-430 nuclear-grade graphite. Material properties for unirradiated graphite IG-430 were determined as follows: specific heat values, as function of temperature, were taken from ASTM (2014); density and expansion coefficients (measured at room temperature, $20^{\circ} \mathrm{C}$ ) were taken from Rohrbaugh (2017) and Swank et al. (2010); and thermal diffusivities for temperature range $20-1000^{\circ} \mathrm{C}$ were taken from Windes et al. (2013). Unirradiated thermal conductivity as a function of temperature is calculated as the product of the diffusivity, specific heat, and density. The effect of irradiation on graphite thermal properties was accounted for by incorporating multipliers for thermal expansion and thermal conductivity, expressed as a function of temperature and fast neutron fluence. These multipliers were taken from the Japanese multiplier data (Shibata et al. 2010) and used to adjust density and thermal conductivity of the graphite holders under actual irradiation conditions.

Heat produced mainly in the fuel compacts and graphite holders was transferred through the gas gaps surrounding the compacts and graphite holders via a gap-conductance model using the gap width and the conductivity of the sweep gas. Heat transfer across every gap was considered by both radiation (15-20\% of the heat transfer depending on the temperature of the compacts) and conduction (80-85\%). Because the thermal capacitance of the sweep gas is very low, advection was not considered in the sweep gas, and it was modeled as stationary. The convective heat transfer from the sweep gas would be $<0.01 \%$ of the heat transfer across the gap because of the low density, low flow rate, and low thermal capacitance. The thermal conductivity of the sweep gas was determined using a set of correlations from Brown University for mixtures of noble gases (Kestin et al. 1984). All gas gaps were modeled as changing linearly with time in response to the graphite dimensional change with fast neutron fluence. The rate of diameter changes for the graphite IG-430 specimens due to fast neutron fluence was taken from (Windes 2012). The gas gap change in thermal models was accomplished by having the gas-gap conductivity of each capsule change with fast neutron fluence.

Like the previous AGR models, the offset of the graphite holder was also considered in the AGR-5/6/7 thermal models. The graphite-holder offset was possibly caused by wearing down of the nubs - due to vibration in the reactor and a slight bit of clearance between the outside of the nubs and the capsule wall - that held the holder away from the capsule wall. The impact of the holder offset can be seen in Figure 8, where the image on the right shows increased temperature on the southwest side, as the holder is offset in the southwest direction, making a bigger gap on the southwest side.

The thermal model provides daily temperature distributions for all components of the AGR-5/6/7 capsules. Figure 9 shows a typical temperature distribution for the entire AGR-5/6/7 test train. As expected, Capsule 3 is the hottest capsule, followed by Capsule 1. Capsule 5 is the coldest of the capsules. Beside temperatures for each finite element of all compacts, the AGR-5/6/7 thermal models also predict temperatures for all TCs. Thus, TC readings during the first cycle (162B) were used for calibration of the AGR-5/6/7 thermal model, adjusting input parameters within their expected ranges to achieve the best match between measured and predicted TCs. Figure 10 shows a history plot of the residual temperatures (measured minus calculated) for all full power days during first four cycles. A modest match between calculated and measured TCs during the first cycle was achieved. The continuing good match between measured and calculated TCs for Cycles 163A-164B indicates that thermal models simulate the thermal conditions well. Capsule 5 shows excellent agreement between the measured and calculated TC temperatures. Capsules 4, 3, and 2 show good agreement, with the average difference being within $40^{\circ} \mathrm{C}$. Capsule 1 has a large variation in predictions compared to actual TCs, but the residuals lie on both sides of the horizontal line at zero, indicating the current model provides a reasonable fit to data. Due to TC failures, especially in the bottom Capsule 1, fewer lines are shown later in the irradiation.

As with the as-run neutronics analysis, verification that the calculation executed properly was done through both technical checkers and post-processing of calculated data. 

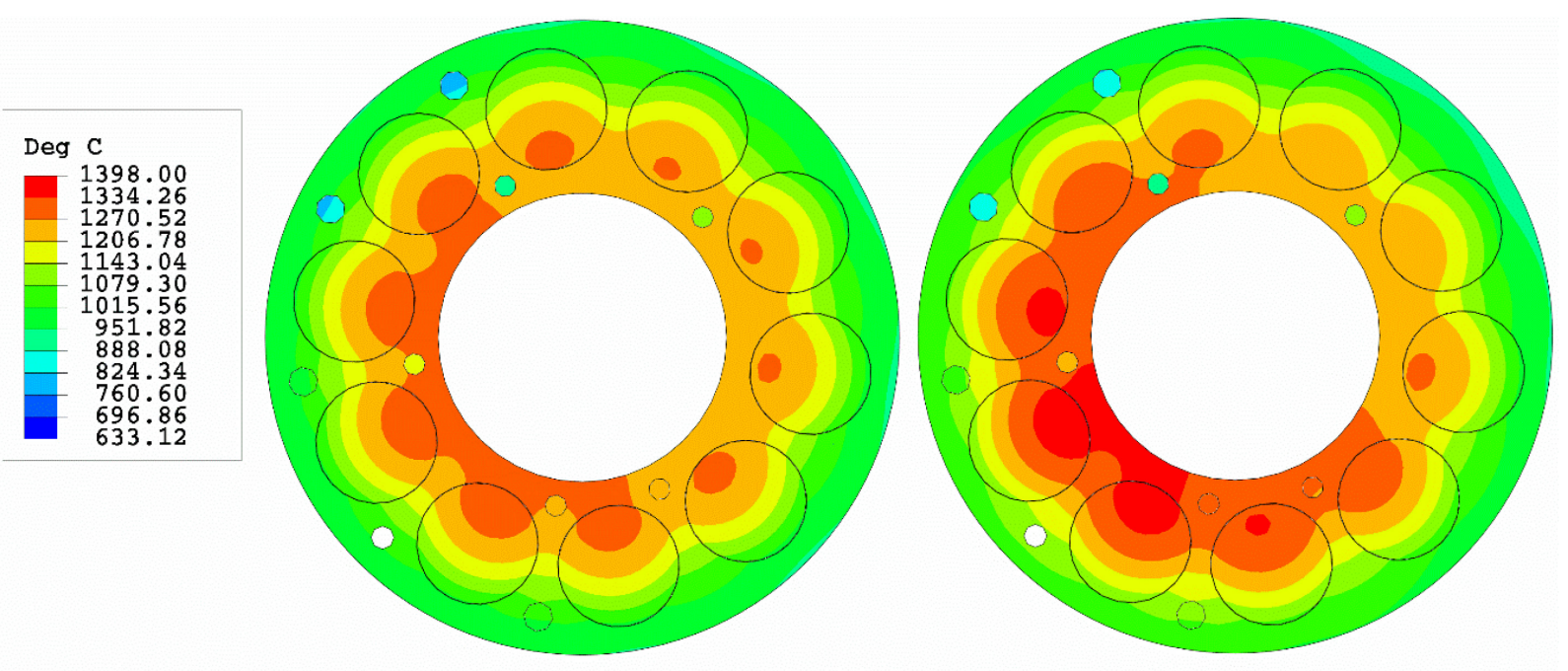

Figure 8. Straight on top-down view temperature contours of the Capsule 1 graphite holder and fuel compacts at axial mid-plane. Left is capsule centered; right is capsule offset $0.0254 \mathrm{~mm}$ in southwest direction.

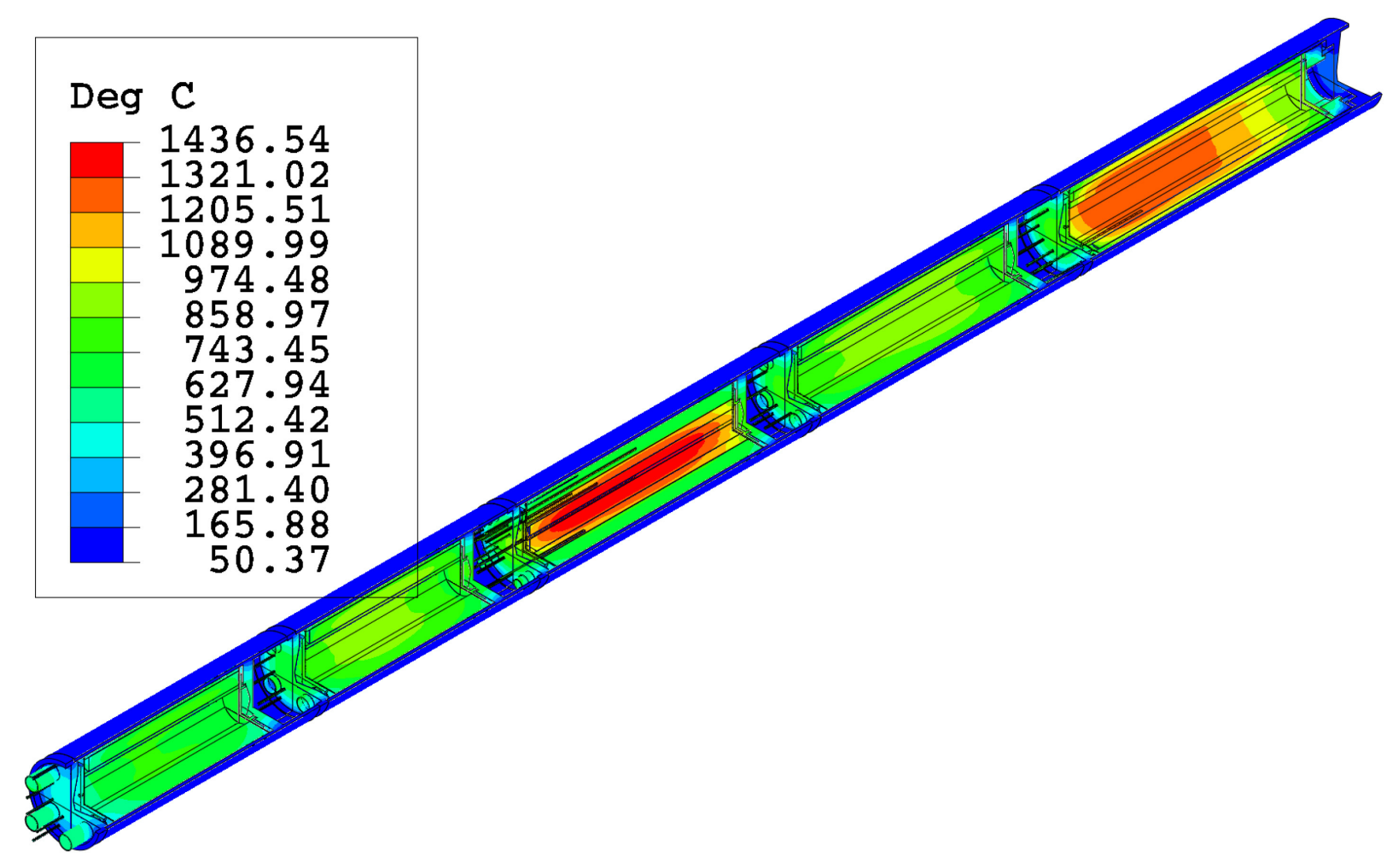

Figure 9. Cut-away view of temperature distribution of entire capsule train. 


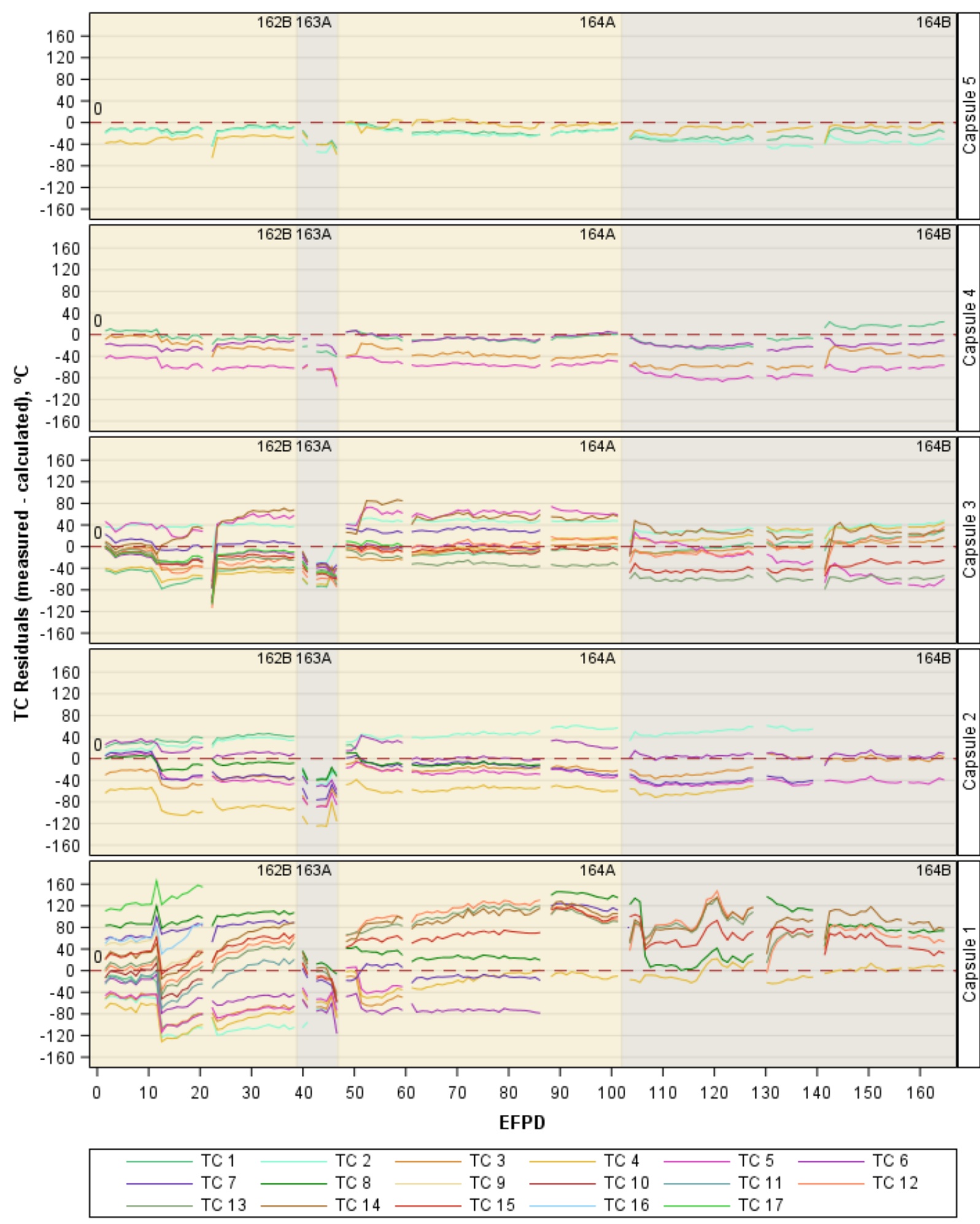

Nuclear Data Management and Analysis System (NDMAS)

Figure 10. Difference between measured and calculated TC temperatures versus EFPD. 


\subsection{Release Rate Calculation}

The radionuclides of interest decay in transit from the capsule to the counters. The actual transport time for each capsule is calculated from outlet-gas flow rates and the capsule-specific volumes through which samples flow to reach the respective monitoring detector. Given a certain measured activity, A $(\mu \mathrm{Ci})$, the radionuclide release rate, $\mathrm{R}$ (atoms/s), of a particular nuclide can be calculated as (Scates 2010):

$$
R=3.7 \times 10^{4} \frac{A e^{\lambda V_{T} / f}}{\left(1-e^{-\lambda V_{S} / f}\right)}
$$

where $V_{S}$ is the sample volume $(\mathrm{mL}), \lambda$ is the nuclide-decay constant $\left(\mathrm{s}^{-1}\right), f$ is the capsule volumetric flow rate $(\mathrm{mL} / \mathrm{s})$, and $V_{T}$ is the transport volume from the capsule to the sample volume $(\mathrm{mL})$. The transport volumes were determined during a lead-out flow test performed at the beginning of the AGR-5/6/7 irradiation. This conversion formula was derived under the assumption that the equilibrium release conditions were established (Scates 2010).

The performance of a nuclear fuel test is typically evaluated using the $\mathrm{R} / \mathrm{B}$ ratio, which is the ratio of the released activity of an isotope from the fuel to the predicted creation rate of the isotope during irradiation. Daily fission-product birth rates for the following isotopes were provided by as-run neutronics calculation: Kr-85m, Kr-87, Kr-88, Kr-89, Kr-90, Xe-131m, Xe-133, Xe-135, Xe-135m, Xe-137, Xe-138, and $\mathrm{Xe}-139$. Release rates obtained from the FPMS and calculated birthrates were used to calculate the $\mathrm{R} / \mathrm{B}$ ratios for the radionuclides of interest. 


\section{DATA MANAGEMENT}

Preservation and management of the AGR experimental data are critical contributions to the experiment's ability to meet its objectives. INL's ART program established the Nuclear Data Management and Analysis System (NDMAS) to ensure that INL ART data are qualified for use and stored in a readily accessible electronic form that can be analyzed to extract useful results. The system is described in the Nuclear Data Management and Analysis System Plan (Hull 2015).

During the entire course of the irradiation period, three streams of data are continually generated:

- Fuel-irradiation data, which include thermocouple readings, sweep-gas flow rates, pressure, and moisture-monitor readings

- FPMS data, which include gross gamma counts

- ATR operating-condition data, which include lobe powers, outer-shim control-cylinder positions, neck-shim positions, and control-rod positions.

AGR-5/6/7 data also comprise the following calculated quantities resulting from release-rate calculations, neutronics modeling, and thermal modeling performed after the end of each ATR cycle:

- Fission-product release-rate data, which include release rates and $\mathrm{R} / \mathrm{B}$ ratios per capsule for twelve krypton and xenon isotopes: $\mathrm{Kr}-85 \mathrm{~m}, \mathrm{Kr}-87, \mathrm{Kr}-88, \mathrm{Kr}-89, \mathrm{Kr}-90, \mathrm{Xe}-131 \mathrm{~m}, \mathrm{Xe}-133, \mathrm{Xe}-135$, Xe-135m, Xe-137, Xe-138, and Xe-139

- Neutronics data, which include fission-power density, fast neutron fluence, burnup for fuel compacts, fission/gamma power density for non-fuel components, and fast neutron fluence for graphite holders

- Thermal data, which include temperatures for fuel compacts and TC locations.

The NDMAS provides a single controlled repository for all AGR-5/6/7 data and makes the data available to users on an easily accessible website. During the experiment, the website shows progress of irradiation in almost real time after data are generated. The data processing is scheduled to run hourly to add new data to the monitoring displays, allowing researchers to quickly identify and correct any issues. The Highcharts JavaScript library is used to generate compact interactive plots that are useful for monitoring of the as-run experimental conditions. Many of the plots in this document are examples of the displays available on the website.

As was done for the previous AGR experiments, detailed model descriptions for the as-run fissionproduct release analysis, thermal analysis, and neutronics analysis will be reported in separate ECARs for each analysis and each experiment. These ECARs serve as the basis for determining qualification status of the calculated results which have been captured and stored in the NDMAS database. Because the corresponding ECARs for AGR-5/6/7 analyses have not yet been issued, all calculated results (R/B ratios, temperatures, and neutronics data) presented in this report are considered preliminary. 


\section{MEASURED AND CALCULATED RESULTS}

The AGR-5/6/7 experiment started on February 16, 2018 (ATR Cycle 162B), and is scheduled to continue through thirteen cycles (i.e., nine regular ATR power cycles and four intermittent high-power powered axial locator mechanism [PALM] cycles), which will bring the total irradiation duration to more than 500 EFPDs. To date, the AGR-5/6/7 capsules have been irradiated for five complete ATR cycles, including three regular cycles (i.e., 162B, 164A, and 164B) and two PALM cycles (163A and 165A). Current cycle is a regular cycle, $166 \mathrm{~A}$, which provides only partial cycle of instrumental data. Calculated results are available only to the end of Cycle 164B. The measured and calculated data are displayed on the 'AGR-5/6/7 Irradiation' webpage for online test-condition monitoring by experiment staff members.

\subsection{Measured Data}

Measurements from instruments in the ATR and AGR-5/6/7 test train are essential for control of the specified experimental irradiations and provide necessary data inputs to simulation codes. The ATR- and capsule-measured data are transferred to the NDMAS and processed automatically almost every hour during the entire irradiation period. A summary of instrumental data is documented below.

\subsubsection{Advanced Test Reactor Power History}

To date, the five complete ATR cycles, including three regular cycles (i.e., 162B, 164A, and 164B) and two PALM cycles (163A and 165A), are listed in (Table 3). The accumulated irradiation time is approximately 174 EFPDs, which is about a third of the planned 500-EFPD schedule.

Table 3. Completed ATR cycles for AGR-5/6/7 irradiation to date.

\begin{tabular}{|c|c|c|c|c|c|c|c|}
\hline $\begin{array}{c}\text { Cycle } \\
\#\end{array}$ & $\begin{array}{c}\text { Cycle } \\
\text { Name }\end{array}$ & $\begin{array}{c}\text { Cycle } \\
\text { Type }\end{array}$ & $\begin{array}{c}\text { Begin } \\
\text { Power Date }\end{array}$ & $\begin{array}{c}\text { End Power } \\
\text { Date }\end{array}$ & $\begin{array}{c}\text { Cycle } \\
\text { Power } \\
\text { Length } \\
\text { (days) }\end{array}$ & $\begin{array}{c}\text { Cycle } \\
\text { Power } \\
\text { Length } \\
\text { (EFPD) }\end{array}$ & $\begin{array}{c}\text { Northeast } \\
\text { Lobe } \\
\text { Power } \\
\text { (MW) }\end{array}$ \\
\hline 1 & $162 \mathrm{~B}$ & Regular & $2 / 16 / 2018$ & $3 / 29 / 2018$ & 41 & $38.5^{\text {(b) }}$ & 14 and 15 \\
\hline 2 & $163 \mathrm{~A}$ & PALM & $4 / 29 / 2018$ & $5 / 8 / 2018$ & 9 & $3.0^{\text {(c) }}$ & 5 and 20 \\
\hline 3 & $164 \mathrm{~A}$ & Regular & $6 / 10 / 2018$ & $8 / 17 / 2018$ & 68 & 54.9 & 16 \\
\hline 4 & $164 \mathrm{~B}$ & Regular & $9 / 18 / 2018$ & $1 / 17 / 2019$ & 121 & $64.1^{\text {(d) }}$ & 17 and 16 \\
\hline 5 & $165 \mathrm{~A}$ & PALM & $2 / 28 / 2019$ & $6 / 18 / 2019$ & 111 & 13.4 & 19 \\
\hline
\end{tabular}

(a) Number of days between the begin-power and end-power for a cycle.

(b) The $162 \mathrm{~A}$ cycle ran 14 days at $14 \mathrm{MW}$ and 25 days at $15 \mathrm{MW}$.

(c) The 163A PALM cycle ran 7 days at $5 \mathrm{MW}$ and 1 days at $20 \mathrm{MW}$.

(d) The $164 \mathrm{~B}$ cycle ran 27 days at $17 \mathrm{MW}$ and 37 days at $16 \mathrm{MW}$.

ATR data that describe the core neutronics and thermal-hydraulic environment are used to inform the physics and thermal analyses, as well as support temperature control. ATR data used as input for the physics analyses include total core power, individual lobe powers, shim cylinder (hafnium absorber) positions, neck shim positions, and regulatory rod positions (see Figure 11). NDMAS receives the ATR operating data at 5-minute increments. Figure 11 is a summary plot of daily operating values for Cycles 162B-166A. 


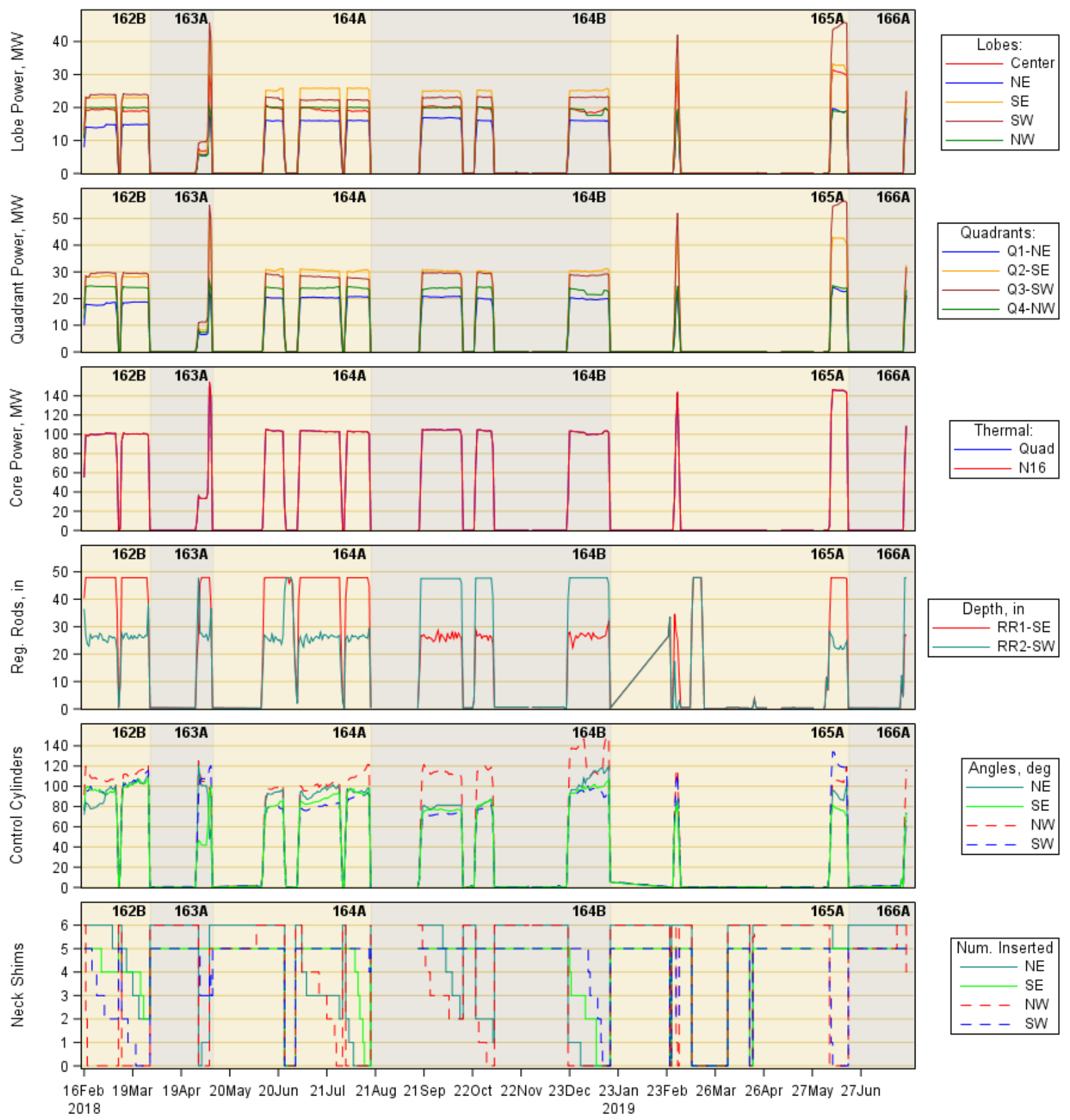

Figure 11. ATR daily operating parameters up to Cycle 166A.

\subsubsection{Sweep Gas Flows}

Several sweep-gas parameters are required for thermal analysis and temperature control. These include pressure, mass-flow rates for each constituent gas, and moisture content. Moisture-content measurements (measured on the outlet side of the capsule and compared to the gas-supply verification measurement) provide indicators of capsule integrity. The lead-out pressure is maintained slightly higher than capsule pressures to prevent crosstalk between gas flows from different capsules. This is because gas from the lead-out can enter capsules, but gas from the capsules cannot enter the lead-out. Sweep-gas constituent mass-flow rates (which determine gas-mixture ratios) will be used in thermal analyses of the test train. The mass-flow rates for each constituent gas, measured at the inlet line for each capsule and the 
lead-out, are referred to as inlet flow rates; the total mass-flow rates, measured at each capsule outlet line, are referred to as outlet flow rates. An additional mass-flow rate is measured at the FPMS. Actual gasflow rates for the five capsules and lead-out are presented in Figure 12 and Figure 13, respectively.

Two problems occurred in the Capsule 1 outlet gas line during Cycles 164B and 165A:

- Shortly after powerup of Cycle 164B (on September 23, 2018), a clog formed somewhere in the Capsule 1 outlet line leading to gas pressure in Capsule 1 increasing beyond its normal level. For part of Cycle 164B, Capsule 1 was operated in a batch mode, where the capsule was isolated and updated gas blends were sent periodically. Eventually, it was determined that at low flow rates, the obstruction growth was halted. For the last half of Cycle 164B, the Capsule 1 flow rate was set at of $11 \mathrm{sccm}$, and no pressure increase was observed.

- During restart of the PALM Cycle 165A (on June 8, 2019), a crack or break in the Capsule 1 gas line occurred somewhere downstream of the clog location, as indicated by a substantial outlet flow increase in Capsule 1 and decrease in the outlet flows of the other four capsules (see the blue line in Figure 12). This is because most of the gas flow from the lead-out flowed into the Capsule 1 outlet line instead of entering other capsules, as designed. This situation was addressed promptly to ensure effective temperature control and accurate fission-gas release measurement for all five capsules.

The following is a log of the operating history for Capsule 1:

- Capsule 1 inlet flow was set to $60 \mathrm{sccm}$ almost from the start of the irradiation until the first week after powerup for Cycle 164B (the fourth cycle). Capsule 1 was the only capsule designed to have no communication with the lead-out. The outlet-flow rate (blue line) was slightly lower than the inlet (red line). Ideally, these two flows should have been identical. The slight difference is likely due to calibration errors between the two instruments.

- The clog, which developed in the Capsule 1 outlet line during Cycle 164B, led the program to periodically shut off the gas flow through this capsule from September 23 to October 16, 2018, while maintaining the same gas mixture to keep the capsule temperature as close to the specification as possible. During this time, no fission-gas release measurements were possible for Capsule 1 because of the intermittent nature of the flow.

- Beginning October 16, 2018, gas flow in Capsule 1 was re-established at $11 \mathrm{sccm}$, which resulted in a stable capsule-inlet pressure. This enabled resumption of the measurement of fission-gas release from Capsule 1.

- At the beginning of the following cycle (165A), a sudden increase in the Capsule 1 outlet flow was observed. This was attributed to a crack or break in the outlet line at a point downstream of the clog. Gas flows to the other capsules were increased to compensate for this new path out of the test. Also, the lead-out flow was increased to $50 \mathrm{sccm}$ (and then $60 \mathrm{sccm}$ ) to ensure lead-out flow was entering Capsules 2-5. During the outage of the following cycle (166A) the inlet- and outlet-gas lines for Capsule 1 were swapped to prevent fission products released by Capsule 1 from spilling to the leadout and entering other capsules. In this new configuration, Capsule 1 inlet gas has the potential of mixing with the lead-out gas due to 'now-inlet' gas line crack or break. Therefore, the neon/helium mixture for the lead-out and Capsule 1 was kept the same, and this allows the Capsule 1 neon fraction to be accurately defined.

- As Cycle 166A progressed, evidence was obtained indicating the hole in the (now) Capsule 1 inlet line was a crack, rather than a complete severing. This is because gas-blend changes on Capsule 1 were reflected very quickly on the control TC readings. If the opening in the line were a complete break, we would expect gas blend changes to be seen slowly in the capsule because of the mixing that would take place in the lead-out. Additionally, as the cycle progressed, the clog appeared to be clearing. The indications are (1) on July 31 at 3:00, the outlet flow on Capsule 1 more than doubled, 
indicating a piece of material making up the clog had broken loose; (2) subsequent to that event, the flow continued to gradually increase for approximately 11 days; and (3) at that point (August 11 (1:00), the flow and pressure in Capsule 1 began a slow exponential rise. Although, no mechanism for this has been identified, the evidence was that the crack was closing: more flow was being forced through Capsule 1. Flows and pressures in the other capsules showed corresponding drops.

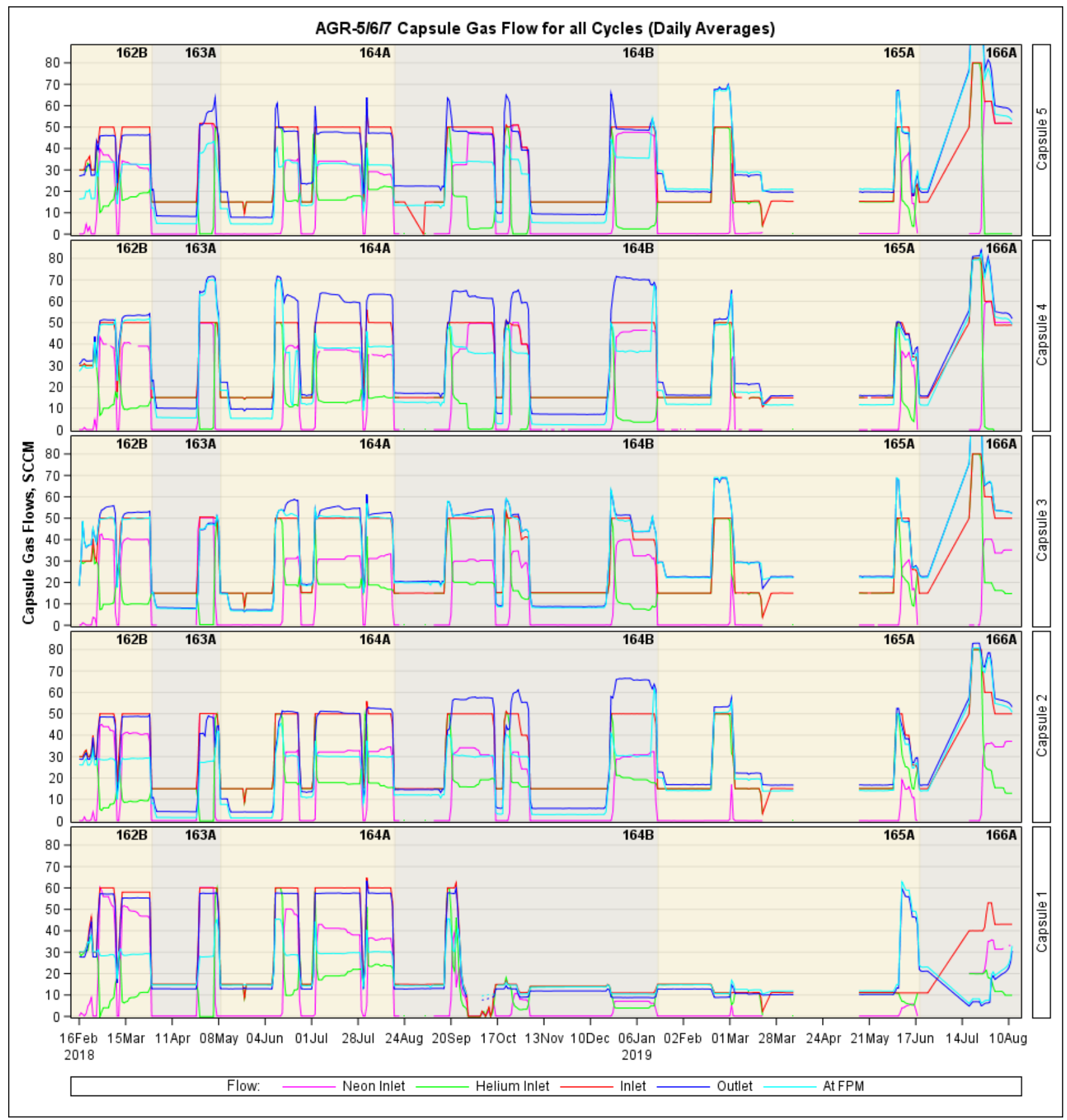

Figure 12. Capsule sweep-gas flow rates. 


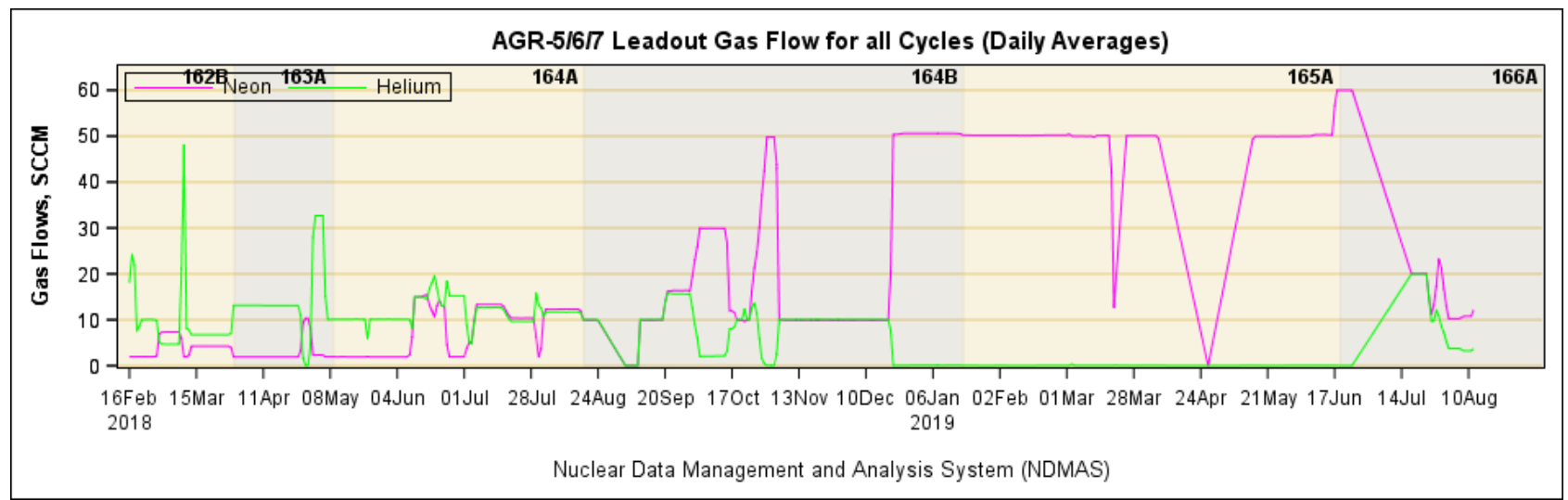

Figure 13. Lead-out sweep-gas flow rates.

\subsubsection{Thermocouple Performance and Data}

By the beginning of Cycle 166A, 38 out of 54 TCs installed in the five AGR-5/6/7 capsules had failed (see Table 4). Among them, 10 TCs in the three upper capsules (3, 4, and 5) were broken before irradiation, during handling and assembling into the test train for inserting to the ATR core. The other 28 TCs failed throughout the irradiation campaign. Most TC failures occurred at scrams, when temperatures dropped rapidly to room temperature after the ATR power dropped from full to zero within approximately 5 minutes. Powering up also causes TC failures, but to a lesser extent because powering up is usually much more gradual than powering down. Failures were identified when TC readings stopped or became stuck at the same level when neighboring TC readings were changing.

To date, TC failures by capsule are

- Capsule 1:16 failed out of 17 installed TCs (the highest number), which led to only one operational TC left in this capsule. This is consistent with TC failures in previous AGR experiments because wires of TCs in the bottom capsule had to pass through all other capsules. Multiple TC failures occurred right from the first cycle, 162B. Interestingly, the surviving TC was exposed to the highest temperature range in this capsule, up to $1400^{\circ} \mathrm{C}$.

- Capsule 2: six TCs failed out of eight installed. These Type N TCs were exposed to lower temperatures (up to $900^{\circ} \mathrm{C}$ ) and started to fail from the third cycle, 164A.

- Capsule 3: six TCs failed during irradiation, and five were broken during assembly out of 17 installed. Note that the failed TCs in this capsule were in both the colder and hotter locations.

- Capsules 4 and 5: no failed TCs during irradiation. This could be because wires of TCs in these capsules do not have to pass through the hottest (Capsule 3). All TC failures (two in Capsule 4 and three in Capsule 5) occurred before irradiation, during handling and assembly.

Figure 14 shows the readings of all functioning TCs as a function of EFPDs; thus, the plots are discontinued at the time of TC failures. Plots for all TCs are mostly parallel to each other, which indicate TCs behave similarly. An exception is TC-5, located in the center of Capsule 3, with gradually decreasing readings during Cycle 164B until its failure on July 26, 2019.

The temperature difference between TCs in the same capsule should remain fairly constant over time. Any other trend or discontinuity in the data suggests that one of the TCs is drifting. Thus, control charts for a pair of the primary- and secondary-control TCs, displayed in the irradiation-monitoring window, are used for monitoring consistency of control TCs. So far, no clear TC drift failures among the control TC pairs in the five AGR-5/6/7 capsules have been observed. 
Table 4. TC failures in AGR-5/6/7 capsules by the end of ATR Cycle 165A (38 failed out of 54).

\begin{tabular}{|c|c|c|c|c|c|c|}
\hline Capsule & $\begin{array}{l}\text { Operational / } \\
\text { Failed TCs }\end{array}$ & Failed TCs & TC Type & Failure Date & $\begin{array}{l}\text { ATR } \\
\text { Cycle }\end{array}$ & $\begin{array}{c}\text { Associated } \\
\text { Event }\end{array}$ \\
\hline \multirow{11}{*}{ (2) } & \multirow{11}{*}{$1 / 16$} & $\begin{array}{l}1 \\
9,10,16,17\end{array}$ & $\begin{array}{l}\text { Cambridge } \\
\text { HTIR }\end{array}$ & $3 / 9 / 2018$ & $162 \mathrm{~B}$ & Scram \\
\hline & & 11 & HTIR & $3 / 29 / 2018$ & $162 \mathrm{~B}$ & Scram \\
\hline & & 2 & Spinel & $5 / 7 / 2018$ & $163 \mathrm{~A}$ & High power \\
\hline & & 3,5 & Cambridge & $6 / 24 / 2018$ & $164 \mathrm{~A}$ & Scram \\
\hline & & 6 & Cambridge & $7 / 30 / 2018$ & $164 \mathrm{~A}$ & Scram \\
\hline & & 7 & Cambridge & $9 / 20 / 2018$ & 164B & Ramp up \\
\hline & & 13 & HTIR & $11 / 5 / 2018$ & $164 \mathrm{~B}$ & Scram \\
\hline & & 8 & Cambridge & $1 / 17 / 2019$ & $164 \mathrm{~B}$ & Scram \\
\hline & & 4 & Cambridge & $6 / 8 / 2019$ & $165 \mathrm{~A}$ & Restart \\
\hline & & 12 & HTIR & $6 / 18 / 2019$ & $165 \mathrm{~A}$ & Scram \\
\hline & & 15 & HTIR & $7 / 25 / 2019$ & $166 \mathrm{~A}$ & Ramp up \\
\hline \multirow{5}{*}{2} & \multirow{5}{*}{$2 / 6$} & 1 & Type N & $6 / 14 / 2018$ & $164 \mathrm{~A}$ & Ramp up \\
\hline & & 8 & Type N & $7 / 30 / 2018$ & $164 \mathrm{~A}$ & Scram \\
\hline & & 4 & Type N & $10 / 24 / 2018$ & $164 \mathrm{~B}$ & Ramp up \\
\hline & & 2,7 & Type N & $11 / 5 / 2018$ & $164 \mathrm{~B}$ & Scram \\
\hline & & 3 & Type $\mathrm{N}$ & $3 / 1 / 2019$ & $165 \mathrm{~A}$ & Scram \\
\hline \multirow{6}{*}{3} & \multirow{6}{*}{$6 / 11$} & $\begin{array}{l}8 \\
9,10,11,16 \\
\end{array}$ & $\begin{array}{l}\text { Cambridge } \\
\text { HTIR }\end{array}$ & Before irradiation & & Broke \\
\hline & & 17 & Cambridge & $6 / 24 / 2018$ & $164 \mathrm{~A}$ & Scram \\
\hline & & 6,7 & Cambridge & $8 / 2 / 2018$ & $164 \mathrm{~A}$ & Restart \\
\hline & & 2 & Spinel & $1 / 17 / 2019$ & $164 \mathrm{~B}$ & Scram \\
\hline & & 15 & Cambridge & $7 / 25 / 2019$ & $166 \mathrm{~A}$ & Ramp up \\
\hline & & 5 & HTIR & $7 / 26 / 2019$ & $166 \mathrm{~A}$ & Ramp up \\
\hline 4 & $4 / 2$ & 2,4 & Type $\mathrm{N}$ & Before irradiation & & Broke \\
\hline 5 & $3 / 3$ & $3,5,6$ & Type N & Before irradiation & & Broke \\
\hline
\end{tabular}




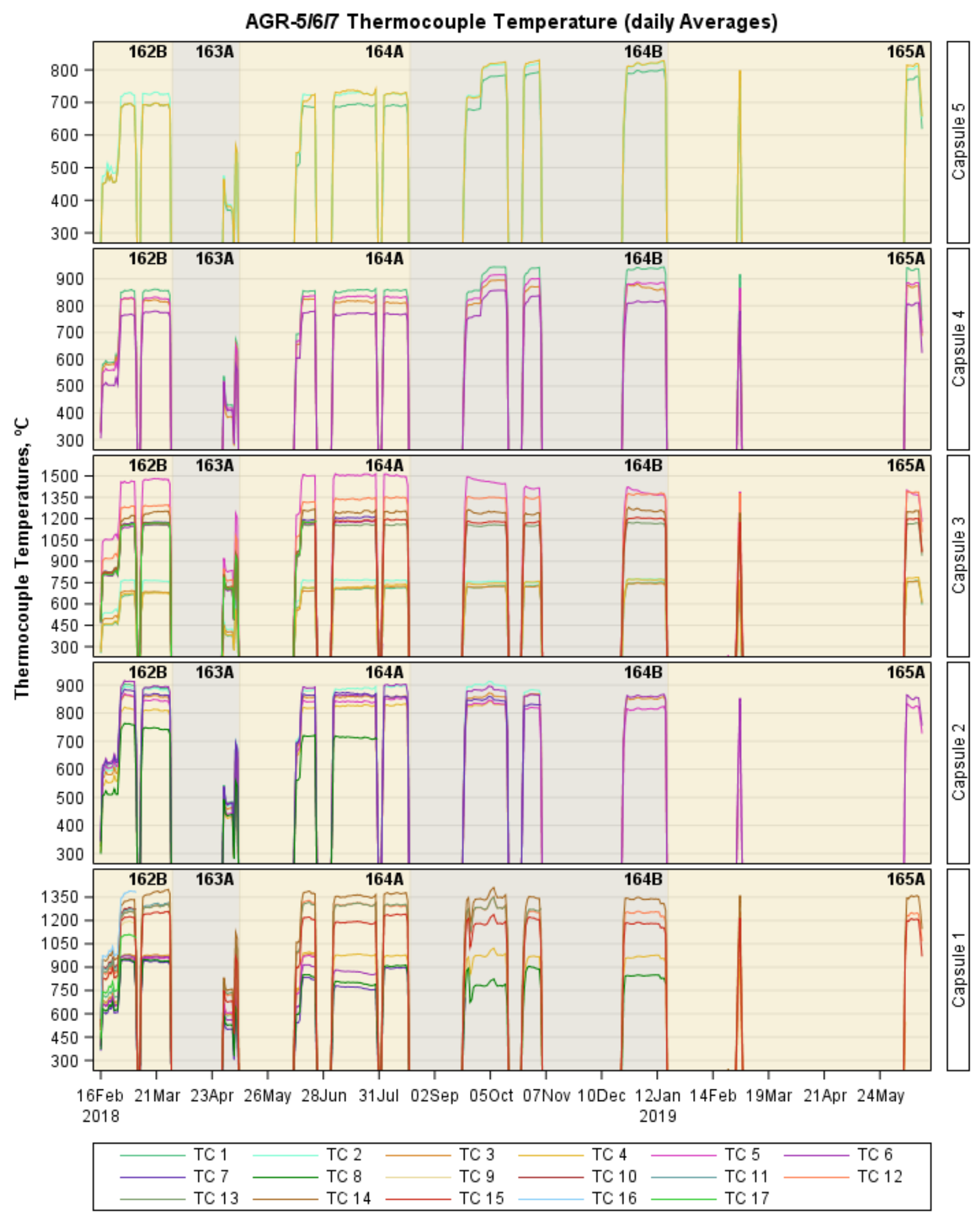

Nuclear Data Management and Analysis System (NDMAS)

Figure 14. Measured TC temperatures. 


\subsection{Calculated Results}

Calculated results for AGR-5/6/7 capsules are also used to control experiment conditions, so they are generated and made available as soon as practically possible. Below is a summary of test-relevant calculated data. including $\mathrm{R} / \mathrm{B}$ ratio, neutronics, and temperature results for the first four cycles: 162B, 163A (PALM), 164A, and 164B.

\subsubsection{Fission-gas Release Rate}

For this report, data on these six isotopes (i.e., $\mathrm{Kr}-85 \mathrm{~m}, \mathrm{Kr}-87, \mathrm{Kr}-88$, $\mathrm{Xe}-135, \mathrm{Xe}-137$, and $\mathrm{Xe}-138$ ) are displayed because they each have a half-life that is sufficiently short to reach equilibrium in the capsule, but also long enough to provide a measurable and stable signal in the FPMS detector.

Release activities are generally reported as an average for the eight-hour interval during normal irradiation conditions to reduce measurement uncertainty. However, during the initial test of the lead-out flow system, release rates were recorded at a much higher frequency (i.e., every 20 minutes), so those measurements usually have higher measurement uncertainty. To preclude the use of data with highmeasurement uncertainty in the analysis of fission-gas release, values where uncertainties are greater than $50 \%$ are omitted. Negative values are also excluded. These data filters remove data from the short leadout flow runs or incomplete measurements while leaving other runs unaffected. The uncertainties of $\mathrm{R} / \mathrm{B}$ data for selected krypton and xenon isotopes are a little more than $6 \%$ on average (see Table 5), except for the shortest-lived isotope, Xe-137, with uncertainty greater than $8 \%$. These AGR-5/6/7 R/B data are considered preliminary until the corresponding ECAR is issued.

Table 5. AGR-5/6/7 measured R/B and uncertainty statistics for selected krypton and xenon isotopes.

\begin{tabular}{|c|c|c|c|c|c|c|}
\hline \multirow{2}{*}{ Isotope } & \multicolumn{3}{|c|}{ Measured R/B } & \multicolumn{3}{c|}{ Uncertainty ${ }^{\text {a }}$ (\%) } \\
\cline { 2 - 7 } & Mean & Minimum & Maximum & Mean & Minimum & Maximum \\
\hline $\mathrm{Kr}-85 \mathrm{~m}$ & $3.538 \mathrm{E}-07$ & $2.152 \mathrm{E}-10$ & $1.948 \mathrm{E}-06$ & 6.7 & 5.8 & 43.0 \\
\hline $\mathrm{Kr}-87$ & $2.344 \mathrm{E}-07$ & $1.159 \mathrm{E}-09$ & $8.261 \mathrm{E}-07$ & 6.3 & 5.8 & 23.1 \\
\hline $\mathrm{Kr}-88$ & $2.881 \mathrm{E}-07$ & $7.347 \mathrm{E}-11$ & $1.109 \mathrm{E}-06$ & 6.9 & 5.8 & 42.3 \\
\hline $\mathrm{Xe}-135$ & $1.466 \mathrm{E}-07$ & $1.123 \mathrm{E}-09$ & $9.091 \mathrm{E}-07$ & 6.7 & 5.8 & 48.5 \\
\hline $\mathrm{Xe}-137$ & $3.089 \mathrm{E}-08$ & $5.337 \mathrm{E}-10$ & $3.163 \mathrm{E}-07$ & 8.7 & 5.8 & 33.8 \\
\hline $\mathrm{Xe}-138$ & $5.187 \mathrm{E}-08$ & $6.466 \mathrm{E}-10$ & $2.427 \mathrm{E}-07$ & 6.2 & 5.8 & 10.2 \\
\hline
\end{tabular}

The daily averages of the R/B in each of the five AGR-5/6/7 capsules for selected krypton and xenon isotopes are presented as a function of irradiation time (in EFPDs) in Figure 15 and Figure 16, respectively. These plots can be used to examine the relationships to fuel temperature and to assess possible particle failures. The following observations can be made:

1. During the regular cycles (i.e., 162B, 164A, and 164B), higher fuel temperatures in Capsules 1 and 3 led to significantly higher R/B values relative to the other three lower-temperature capsules (i.e., 2, 4, and 5). Lower fuel temperatures at the beginning of each cycle clearly led to lower R/B in all the capsules.

2. During the short PALM Cycle 163A, the ATR only reached full power for one day at the end of the cycle, which led to much lower fuel temperatures in all capsules for most of that cycle. Therefore, $\mathrm{R} / \mathrm{B}$ data are much lower during Cycle 163A.

3. The Capsule 1 gas-line issues described in Section 5.1.2 began during Cycle 164B. As a result, R/B data during the first half of 164B were somewhat unstable before returning to normal levels (see 
bottom panels of Figure 15 and Figure 16). Therefore, unstable Capsule 1 R/B data during approximately the first 30 days of Cycle 164B should be excluded from the R/B analysis.

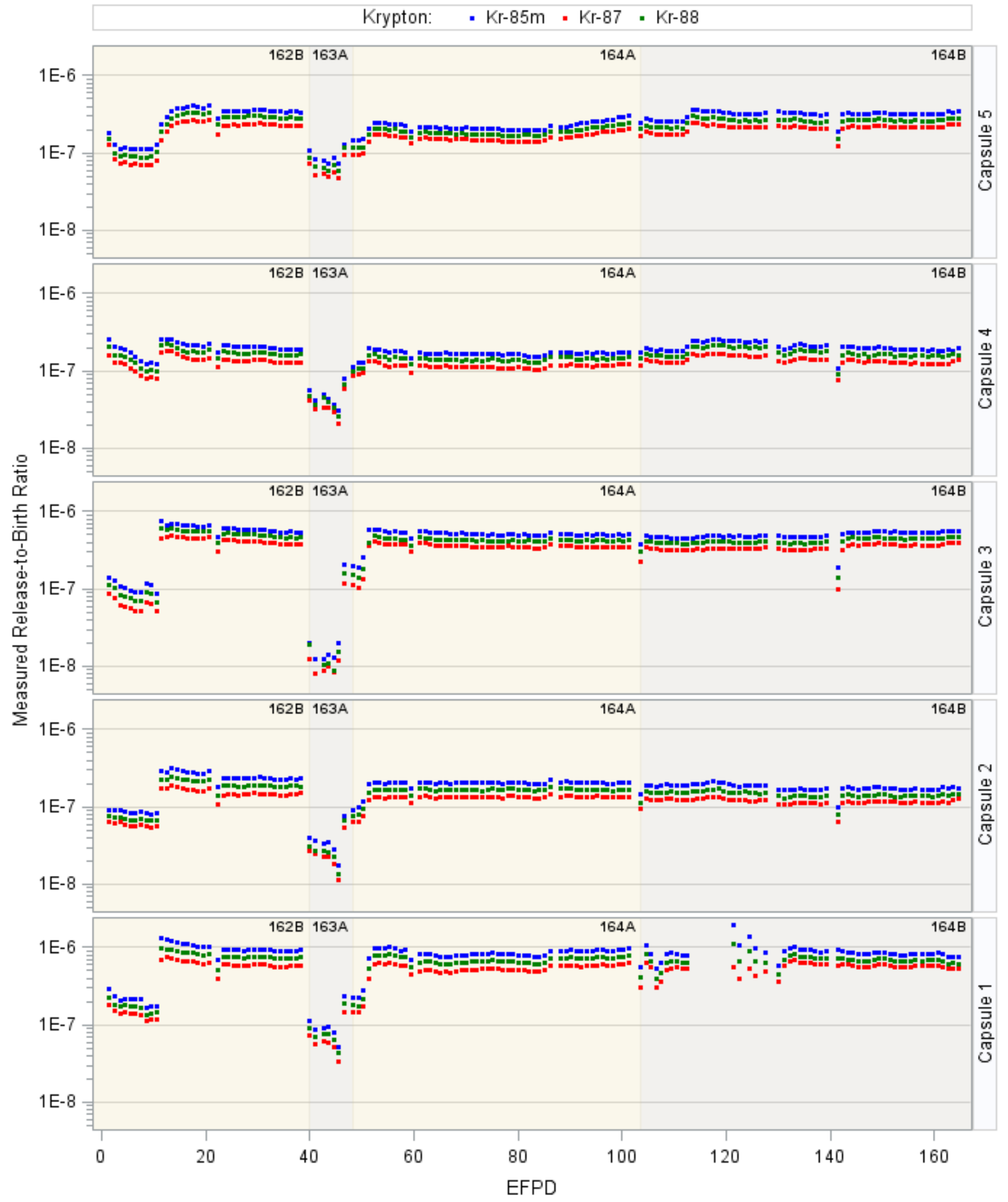

Figure 15. Measured R/B in AGR-5/6/7 capsules for krypton isotopes. 


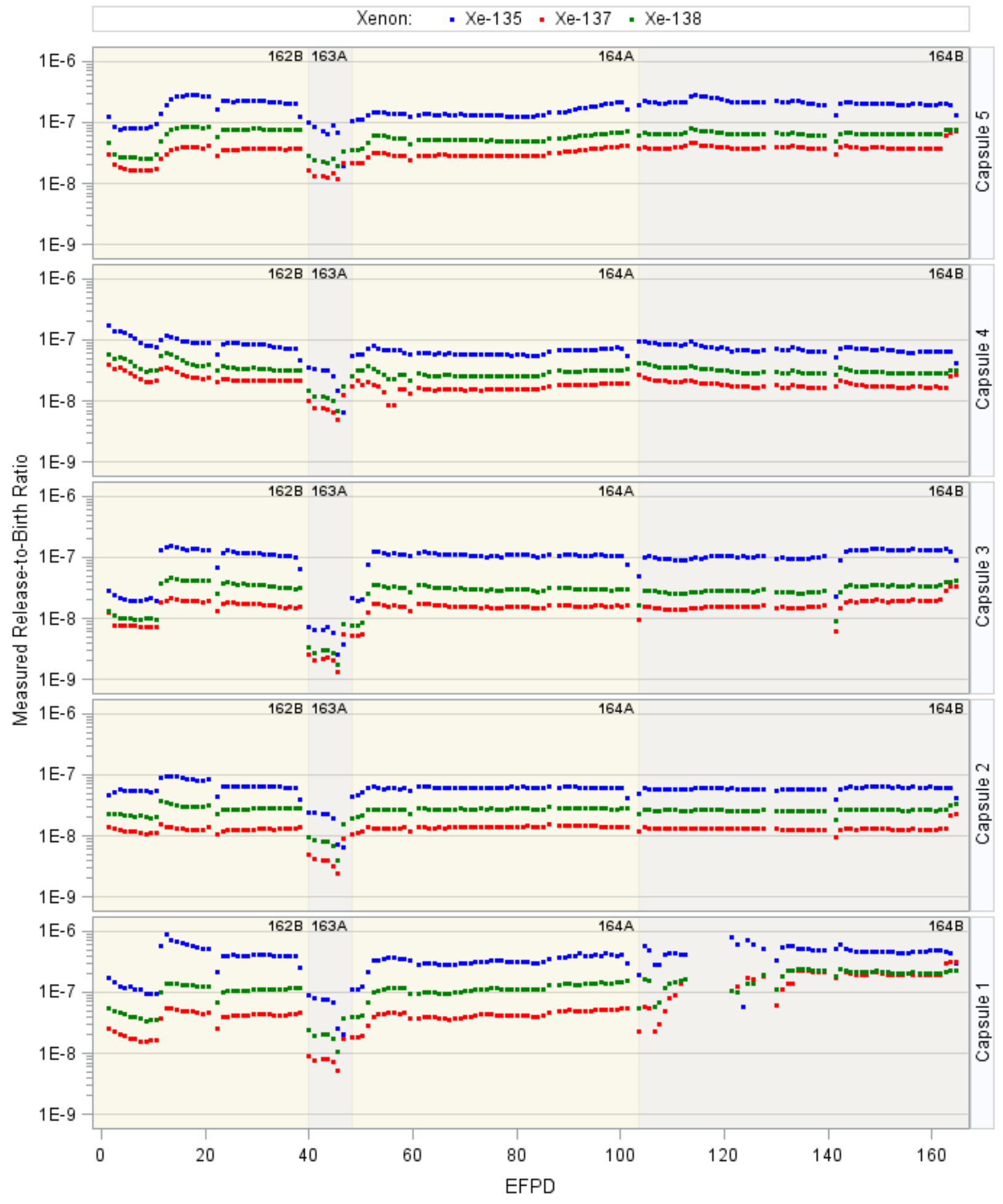

Figure 16. Measured R/B in AGR-5/6/7 capsules for xenon isotopes. 


\subsubsection{As-run Neutronics Analysis Results}

The neutronics analysis provides daily values of fission power density $\left(\mathrm{W} / \mathrm{cm}^{3}\right)$ and fast neutron fluence $\left(\mathrm{n} / \mathrm{m}^{2}\right)$ for 194 AGR-5/6/7 compacts and non-fuel components, and burnup (\%FIMA) for all compacts. Fast neutron fluence is defined as those neutrons with energies greater than $0.18 \mathrm{MeV}$. For each time step, neutronics data include:

- For fuel compacts: 776 values of fission power density and fast neutron fluence (4 axial segments per compact); and 194 values of burnup (one per compact)

- For non-fuel components: 907 values of neutron and gamma heat rates for graphite holders, capsule shell, neutron filters (shrouds), capsule lids, spacers, thru tubes, TCs, and gas lines; 45 values of fast neutron fluence for graphite holders in five capsules.

The daily power per particle in milliwatts per particle are converted from the provided fission power density, compact volume, and number of particles per compact. The daily capsule-peak power per particle plots in Figure 17 show that, so far, the AGR-5/6/7 compacts meet the requirement of SPC-1352 -i.e., "The instantaneous peak power per particle shall be $\leq 400 \mathrm{~mW} /$ particle."

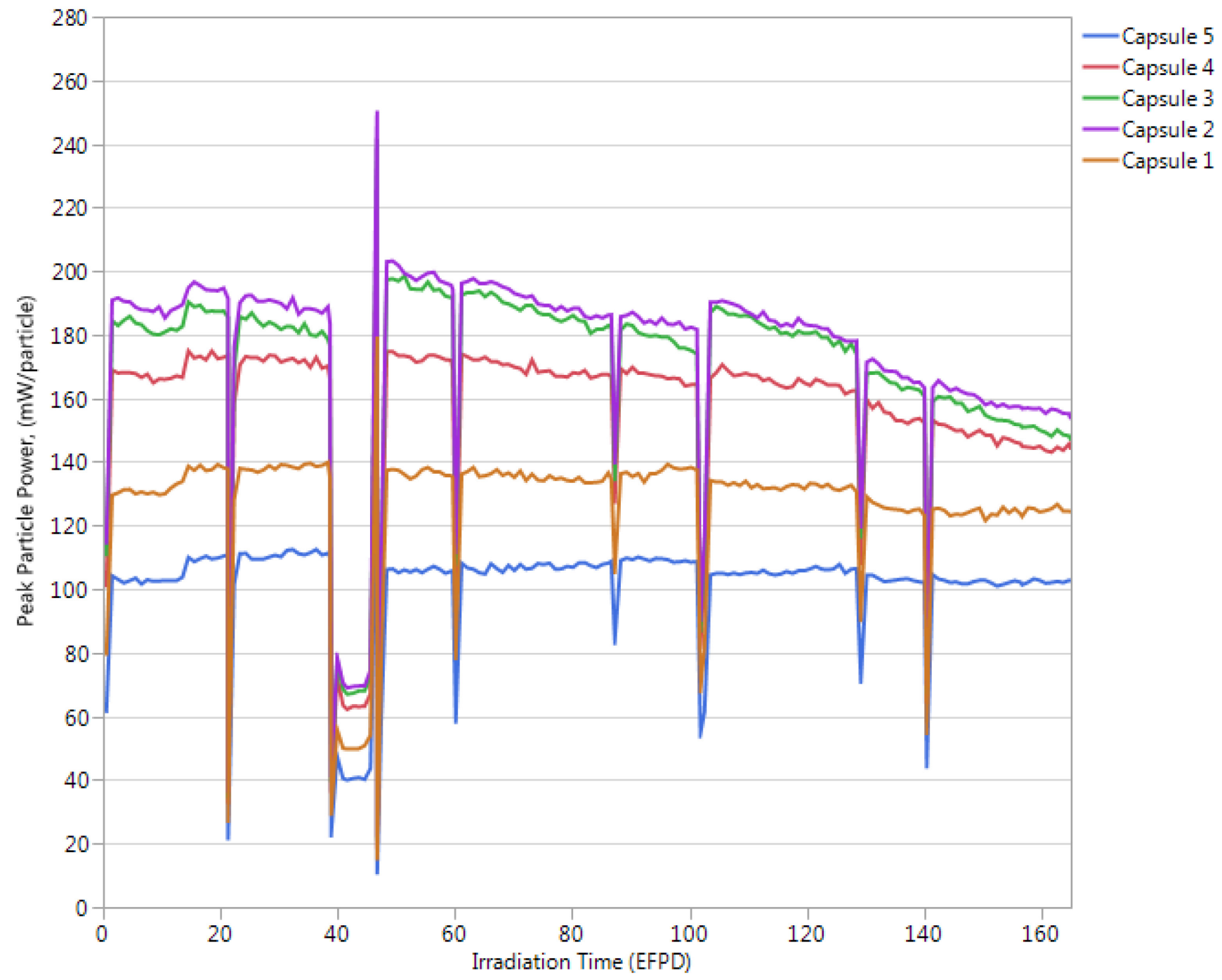

Figure 17. Calculated daily capsule-peak particle power. 
For each compact, minimum, average, and maximum values are calculated based on the provided values from the four axial segments per compact. Then, for each capsule, these values are calculated from per-compact values. The daily calculated compact power densities are plotted versus irradiation time by capsule in Figure 18, compact burnups are in Figure 19, and fast neutron fluences are given in Figure 20. The power density in the three middle capsules $(2,3$, and 4$)$ decreased more rapidly as each cycle progressed than in the two peripheral capsules (1 and 5), as shown in Figure 18. Capsules 2 and 3 were near the ATR core midplane and exposed to the highest thermal-neutron levels (Table 6). Thus, their compacts sustained the greatest burnups (Figure 19) and fluence (Figure 20). Capsule 4 was exposed to slightly lower thermal-neutron levels, which led to less burnup and fluence. The bottom Capsules 1 and top Capsule 5 received less fast fluence and accumulated less burnup. The average burnup and fast neutron fluence, accumulated at the end of Cycle 164B, for each of 194 compacts are presented in Appendix A.

The burnup and fast neutron values for AGR-5/6/7 test fuel reached about one-third of their requirements by the end of Cycle 164B, after approximately 160 EFPDs of irradiation (which is also a little less than one-third of the 500-EFPD schedule specified in PLN-5245).

Table 6. Minimum, average, and peak compact burnup and fast fluence at the end of 164B.

\begin{tabular}{|c|c|c|c|c|c|c|}
\hline \multirow{3}{*}{ Capsule } & \multicolumn{3}{|c|}{$\begin{array}{c}\text { Compact Burnup } \\
\text { (\% FIMA) }\end{array}$} & \multicolumn{3}{c|}{$\begin{array}{c}\text { Compact Fast Neutron Fluence } \\
\left(10^{25} \mathrm{n} / \mathrm{m}^{2}, \mathrm{E}>0.18 \mathrm{MeV}\right)\end{array}$} \\
\cline { 2 - 7 } & \multicolumn{2}{|c|}{$\begin{array}{c}\text { Specification at the end of irradiation: } \\
\text { Minimum }>6 \% \text { for all compacts } \\
\text { Maximum }>18 \% \text { for at least one compact }\end{array}$} & $\begin{array}{c}\text { Specification at the end of irradiation: } \\
\text { Minimum }>1.5 \text { for all compacts } \\
\text { Maximum } \leq 7.5 \text { for all compacts and } \geq 5.0 \text { for } \\
\text { at least one compact. }\end{array}$ \\
\cline { 2 - 7 } & $\begin{array}{c}\text { Minimum } \\
\text { Compact }\end{array}$ & $\begin{array}{c}\text { Capsule } \\
\text { Average }\end{array}$ & $\begin{array}{c}\text { Peak } \\
\text { Compact }\end{array}$ & $\begin{array}{c}\text { Minimum } \\
\text { Compact }\end{array}$ & $\begin{array}{c}\text { Capsule } \\
\text { Average }\end{array}$ & $\begin{array}{c}\text { Peak } \\
\text { Compact }\end{array}$ \\
\hline 5 & 3.14 & 3.90 & 4.45 & 0.73 & 1.11 & 1.45 \\
\hline 4 & 6.11 & 6.67 & 7.01 & 1.70 & 1.92 & 2.11 \\
\hline 3 & 6.72 & 7.30 & 7.62 & 2.16 & 2.26 & 2.31 \\
\hline 2 & 6.78 & 7.48 & 7.81 & 1.91 & 2.11 & 2.26 \\
\hline 1 & 2.50 & 4.36 & 5.54 & 0.69 & 1.36 & 1.87 \\
\hline
\end{tabular}




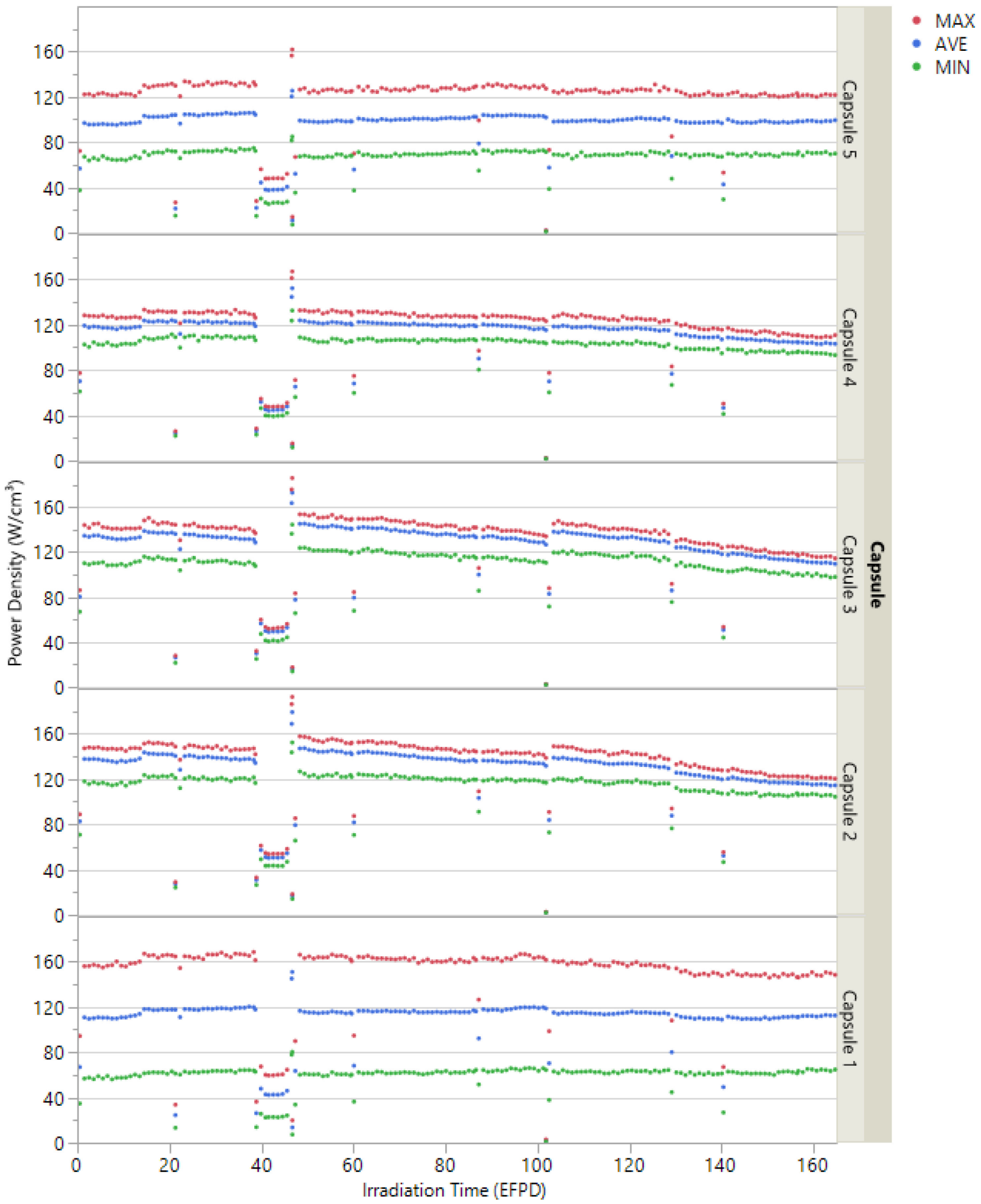

Figure 18. Calculated daily minimum, maximum, and volume-averaged compact power density. 


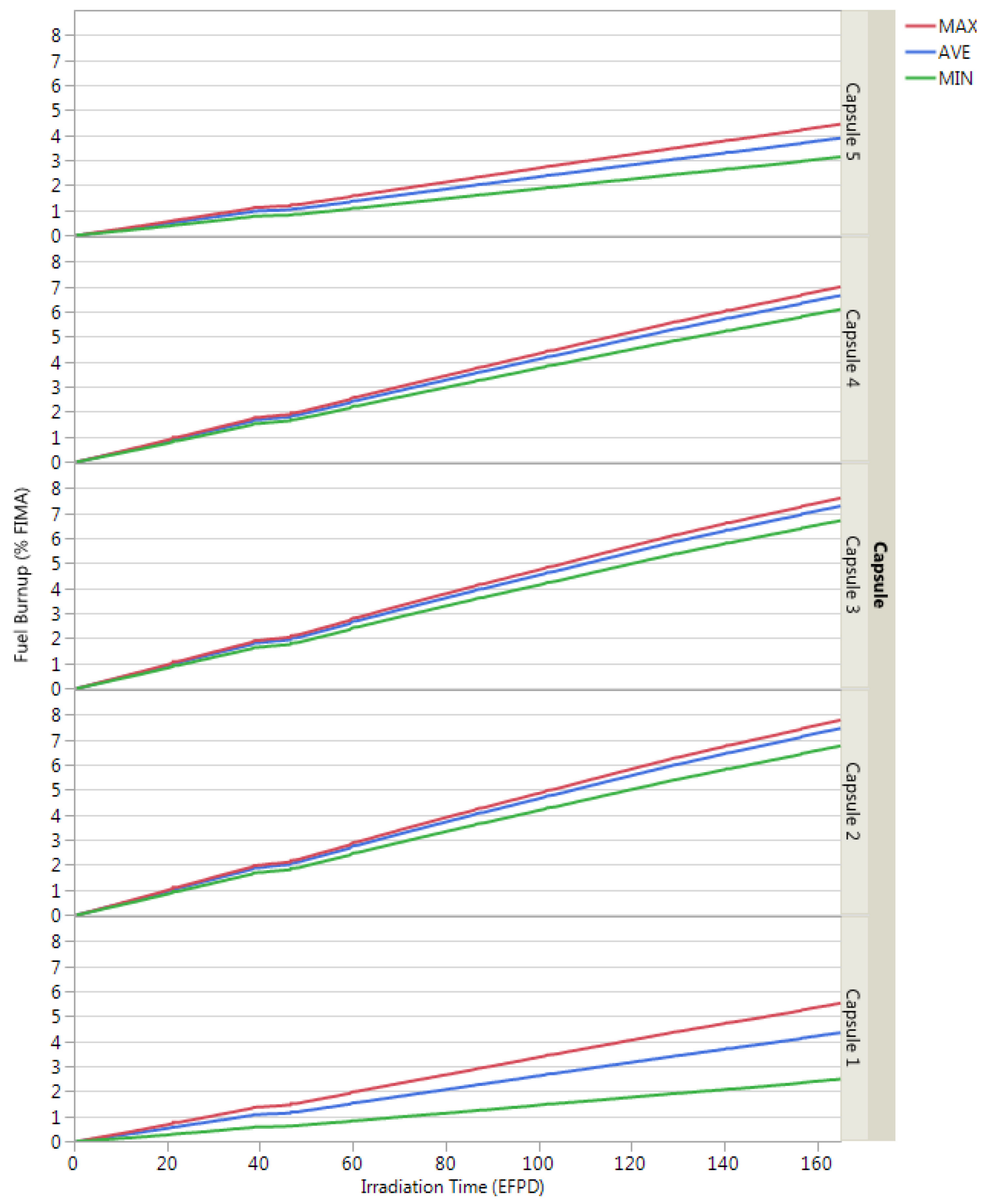

Figure 19. Burnup versus irradiation time in EFPD. 


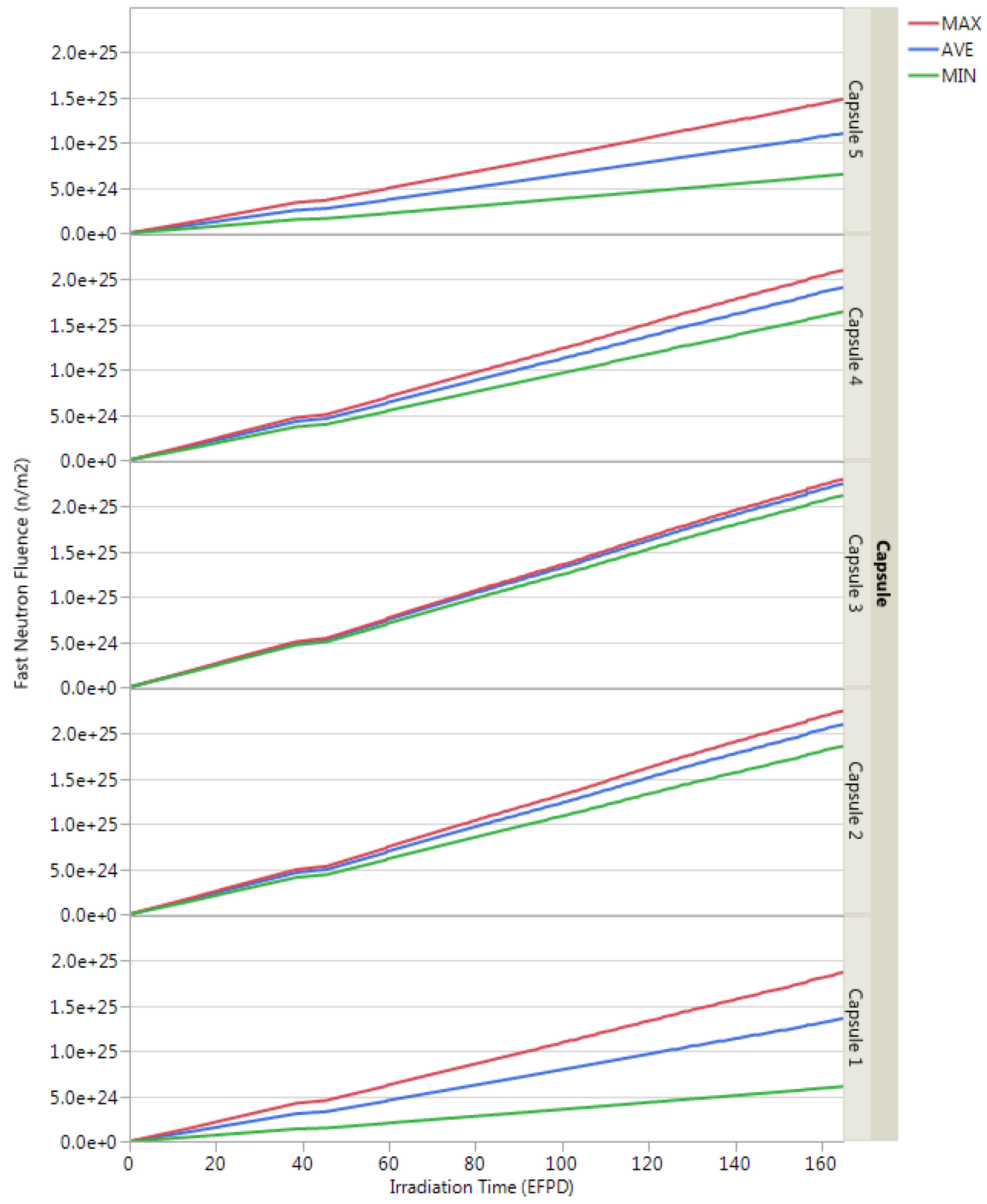

Figure 20. Fast neutron fluence $(\mathrm{E}>0.18 \mathrm{MeV})$ versus irradiation time in EFPD 


\subsubsection{As-Run Thermal Analysis Results}

The AGR-5/6/7 thermal model provides detailed temperatures calculated for each finite-element volume of 194 fuel compacts for each time step (or each day). These temperatures are used to calculate instantaneous and time-averaged minimum, volume-averaged, and peak fuel temperatures per compact and per capsule, which are presented in Figure 21 and Figure 22, respectively. The minimum, volumeaverage, and peak values of time-averaged compact temperature at the end of Cycle 164B are presented in Table 7 for each capsule and each experiment. The minimum, volume-averaged and peak values of timeaveraged temperatures at the end of Cycle 164B for each of 194 compacts are presented in Appendix A.

The daily peak temperature from all capsules is $1495^{\circ} \mathrm{C}$, which is well below the specification of $1800^{\circ} \mathrm{C}$. Thus, this constraint was met in all capsules (as can be seen in Figure 21). The instantaneous fuel temperatures in Capsules 1-3 remained relatively constant, except for the first 10 days of 162B and the PALM cycle 163A. Increasing fuel temperatures in Capsules 4 and 5 after 110 EFPDs are the result of increasing the control TC setpoint by $90^{\circ} \mathrm{C}$ during Cycle 164B.

Table 7. Compact temperature per capsule and experiment at the end of 164B.

\begin{tabular}{|l|l|l|l|}
\hline Capsule and Experiment & $\begin{array}{l}\text { Time-Averaged } \\
\text { Minimum } \\
\text { Temperature }\left({ }^{\circ} \mathrm{C}\right)\end{array}$ & $\begin{array}{l}\text { Time-Averaged } \\
\text { Volume-Averaged } \\
\text { Temperature }\left({ }^{\circ} \mathrm{C}\right)\end{array}$ & $\begin{array}{l}\text { Time-Averaged } \\
\text { Peak } \\
\text { Temperature }\left({ }^{\circ} \mathrm{C}\right)\end{array}$ \\
\hline All Capsule 5 compacts & 451 & 705 & 800 \\
\hline All Capsule 4 compacts & 545 & 816 & 920 \\
\hline All Capsule 2 compacts & 538 & 804 & 912 \\
\hline All Capsule 1 compacts & 607 & 1002 & 1224 \\
\hline All AGR-5/6 compacts & $\mathbf{4 5 1}$ & $\mathbf{8 9 7}$ & $\mathbf{1 2 2 4}$ \\
\hline All AGR-7 Capsule 3 compacts & $\mathbf{9 3 3}$ & $\mathbf{1 2 5 5}$ & $\mathbf{1 3 8 1}$ \\
\hline
\end{tabular}

These daily fuel temperatures are also used to calculate fractions of fuel that were exposed to each temperature range in order to compare against fuel-temperature specifications. Table 8 presents fractions of fuel exposed to each temperature range and contributing capsules. Fuel temperature specifications for AGR-5/6 and AGR-7 are also included for comparison. These results indicate that calculated timeaveraged fuel temperatures by the end of 164B cycle are lower than specifications.

Table 8. Time-averaged temperature at the end of 164B (Note: fuel distribution calculation excludes extreme low-temperature periods at the beginning of the first cycle 162B and the PALM cycle 163A).

\begin{tabular}{|c|c|c|c|}
\hline Temperature range & Contributing capsule(s) & Actual data & Specification \\
\hline \multicolumn{4}{|l|}{ AGR-5/6 Experiment } \\
\hline$\geq 600{ }^{\circ} \mathrm{C}$ and $<900{ }^{\circ} \mathrm{C}$ & $1,2,4,5$ & $41.0 \%$ & $30 \%$ \\
\hline$\geq 900^{\circ} \mathrm{C}$ and $<1050^{\circ} \mathrm{C}$ & $1,2,4$ & $25.3 \%$ & $30 \%$ \\
\hline$\geq 1050^{\circ} \mathrm{C}$ and $<1250^{\circ} \mathrm{C}$ & 1 & $30.7 \%$ & $30 \%$ \\
\hline$\geq 1250^{\circ} \mathrm{C}$ and $<1400{ }^{\circ} \mathrm{C}$ & 1 & $2.7 \%$ & $10 \%$ \\
\hline \multicolumn{2}{|c|}{ Time average, peak temperature } & $1224^{\circ} \mathrm{C}$ & $1350 \pm 50^{\circ} \mathrm{C}$ \\
\hline \multicolumn{2}{|c|}{ Time average, minimum temperature } & $451^{\circ} \mathrm{C}$ & $\leq 700{ }^{\circ} \mathrm{C}$ \\
\hline \multicolumn{4}{|c|}{ AGR-7 Experiment - Capsule 3} \\
\hline \multicolumn{2}{|c|}{ Time average, peak temperature } & $1381{ }^{\circ} \mathrm{C}$ & $1500 \pm 50^{\circ} \mathrm{C}$ \\
\hline
\end{tabular}




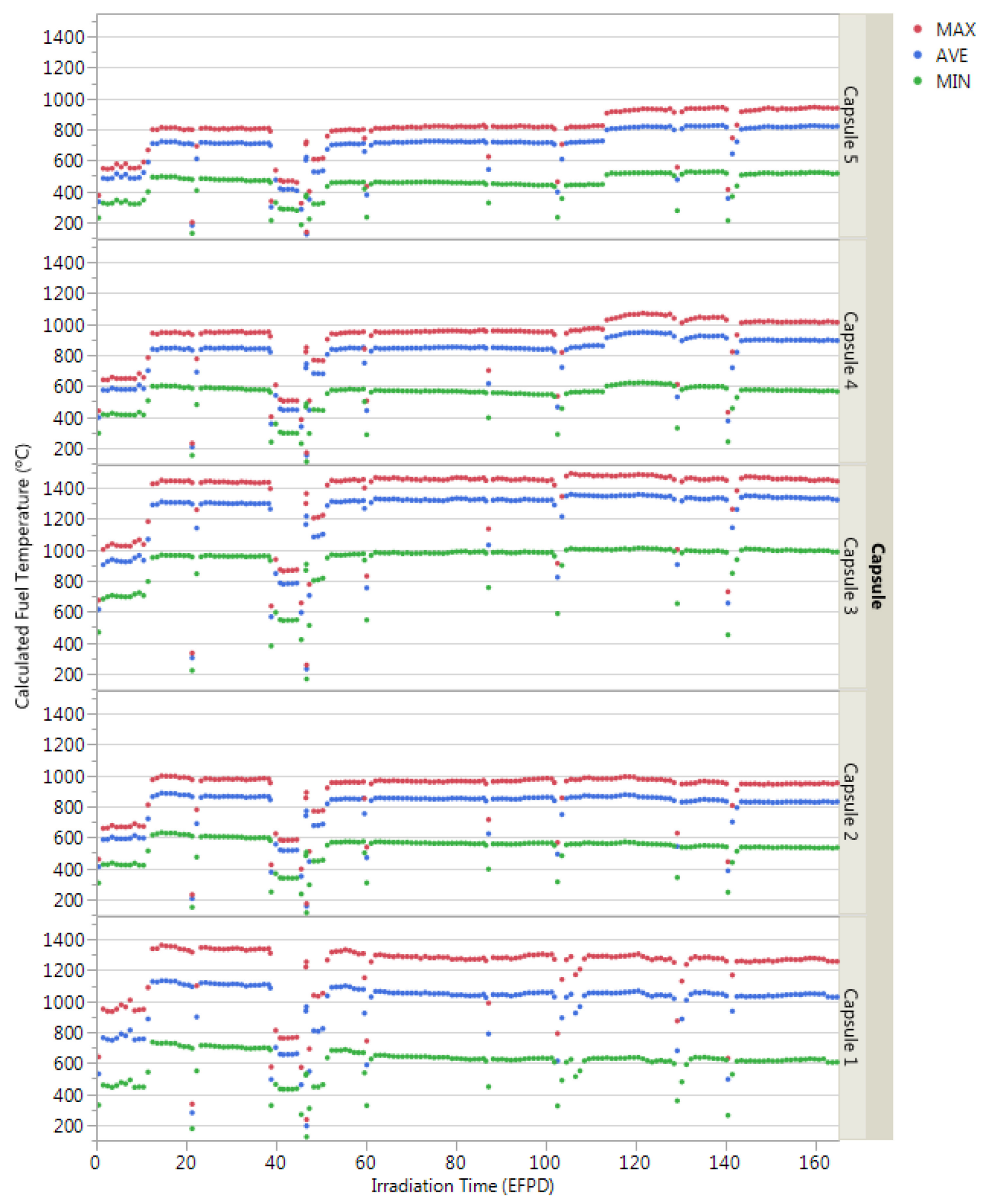

Figure 21. Calculated daily minimum, maximum, and volume-averaged fuel temperatures. 


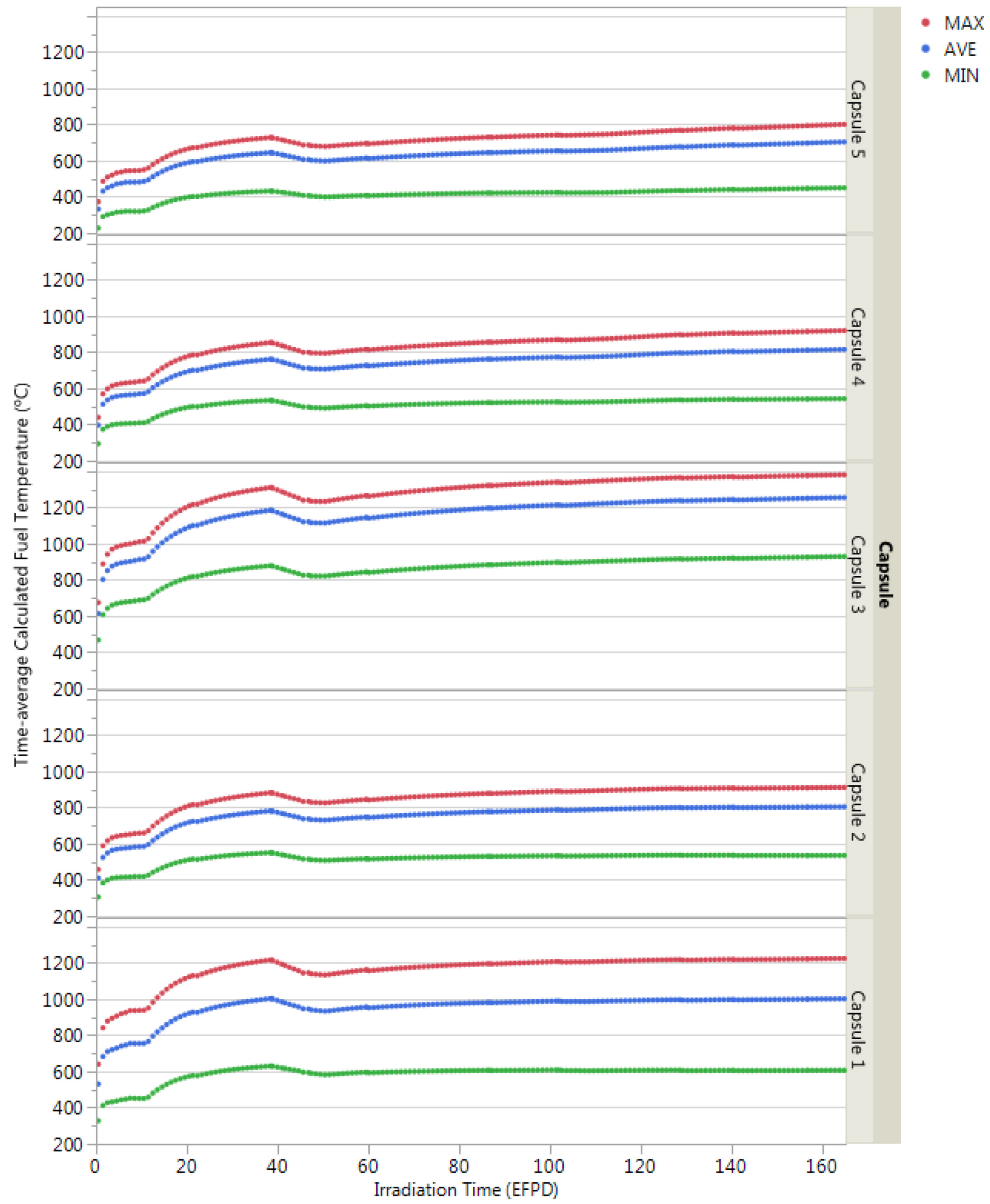

Figure 22. Calculated time-averaged minimum, time-averaged maximum, and time-averaged volumeaveraged fuel temperatures. 


\subsection{Fuel Temperature Control}

A range of irradiation fuel temperatures were specified for each AGR-5/6/7 capsule in order to achieve the desired fuel-compact temperature distribution in the test train (per SPC-1352). The goal for AGR-5/6 is to adequately bound the irradiation conditions expected in an HTGR, which led to timeaveraged irradiation temperatures from less than $900^{\circ} \mathrm{C}$ to over $1250^{\circ} \mathrm{C}$ that will conservatively span the range expected in a prismatic reactor. The primary goal of AGR-7 is to margin test UCO fuel; thus, its fuel is tested at a higher time-averaged peak temperature of $1500^{\circ} \mathrm{C}$. To shape the temporal and spatial fuel power distribution (subsequently, fuel temperature distribution) in the capsules, two techniques are used to adjust the neutron-flux incident to the AGR 5/6/7 test train. These techniques include placing a neutron filter around the capsules and raising the power throughout the irradiation, as discussed in Section 2.1 .

Before irradiation, preliminary neutronics and thermal analyses were performed for AGR-5/6/7 capsules based on the hypothetical 13-cycle schedule, as documented in ECAR-2961 and ECAR-2966, respectively. Besides confirming the AGR-5/6/7 requirements of fast fluence and burnup are met, the neutronics analysis provides heat rates and fast fluence for input to the thermal models. In turn, the thermal analysis provides confirmation that the chosen gas-gap widths and gas mixtures will allow the test fuel to meet the temperature requirements. The predicted fuel and TC temperatures were also used to determine corresponding setpoint temperatures for the designated control TC for each capsule. Beside the primary control TC, other two TCs were selected as a backup and second backup TC for use in the event of primary TC failure. Corresponding setpoint temperatures are also defined to these backup TCs.

During irradiation, instantaneous temperature control is based on temperature feedback from the designated control TC for each capsule and is performed by varying the sweep-gas composition (between $100 \%$ helium for high conductivity and $100 \%$ neon for low conductivity). A single blend of inert gases from a capsule-specific gas controller is routed by an independent gas line to each capsule to provide temperature control.

The control TC setpoints are periodically adjusted in response to changing events in a capsule, events such as TC drift, irradiation-induced changes in gas-gap widths and material thermal conductivities, and replacement of the designated control TC due to failure. These TC setpoint adjustments are based on fuel temperatures, as calculated by the as-run thermal analysis. After completion of each cycle, the as-run thermal analysis is performed based on the fast fluence and heat rate (predicted by the as-run neutronics analysis using actual ATR operating conditions) and actual neon/helium gas mixtures in AGR-5/6/7 capsules. Calculated fuel temperatures are compared against requirements, as shown by plots in Figure 23 for AGR-5/6 and Figure 24 for AGR-7. The contribution of the fuel portion from each capsule to each temperature range was color-coded and displayed in these interactive plots. Therefore, based on these plots, control TC setpoints will be adjusted accordingly to improve the match with fuel-temperature requirements.

For AGR-5/6 capsules (Figure 23), the low portion of fuel in the middle range of temperatures (i.e., $900-1050^{\circ} \mathrm{C}$ ) at the end of Cycle 164A prompted the first TC setpoint adjustment on September 30, 2018 (Cycle 164B), when the control TC setpoints for Capsules 4 and 5 were raised by $90^{\circ} \mathrm{C}$ to increase fuel temperatures. As a result, the portion of AGR-5/6 fuel in the $900-1050^{\circ} \mathrm{C}$ range increased from 20 to $25 \%$, which is closer to the $30 \%$ requirement. In addition, and the TC setpoint in Capsule 2 has been increased by $40^{\circ} \mathrm{C}$ for the current cycle, $166 \mathrm{~A}$. On the other hand, the decreasing fraction of fuel for the highest range (i.e., $1250-1350^{\circ} \mathrm{C}$ ) is caused by a decrease in Capsule 1 fuel temperatures over time. In order to meet the requirement for this temperature range, the TC setpoint for Capsule 1 will be increased after the issue with the capsule gas line is resolved.

For AGR-7 Capsule 3, the calculated time-averaged peak fuel temperature by the end of Cycle 164B was lower than the specification $\left(1381^{\circ} \mathrm{C}\right.$ actual versus $1500^{\circ} \mathrm{C}$ required, as shown in Table 8). Figure 24 
also shows only $\sim 0.5 \%$ of Capsule 3 fuel experienced time-averaged temperature $>1450^{\circ} \mathrm{C}$ range. Therefore, TC setpoint for Capsule 3 has been increased by $50^{\circ} \mathrm{C}$ for the current cycle, $166 \mathrm{~A}$.

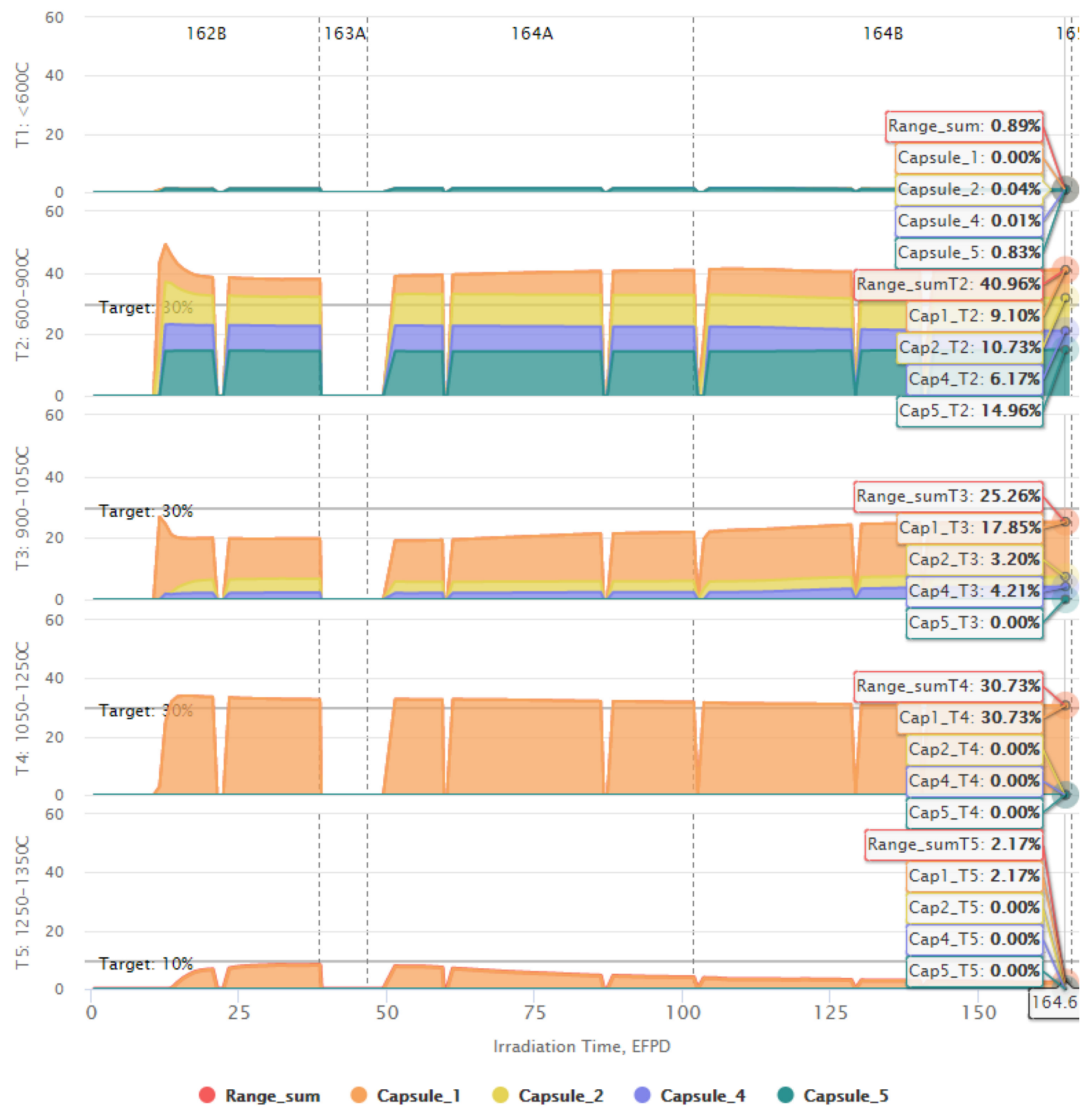

Figure 23. Time-averaged fuel temperature fraction by range for AGR-5/6 capsules (only days when control TC reached setpoint temperature are included in the time averaging). 


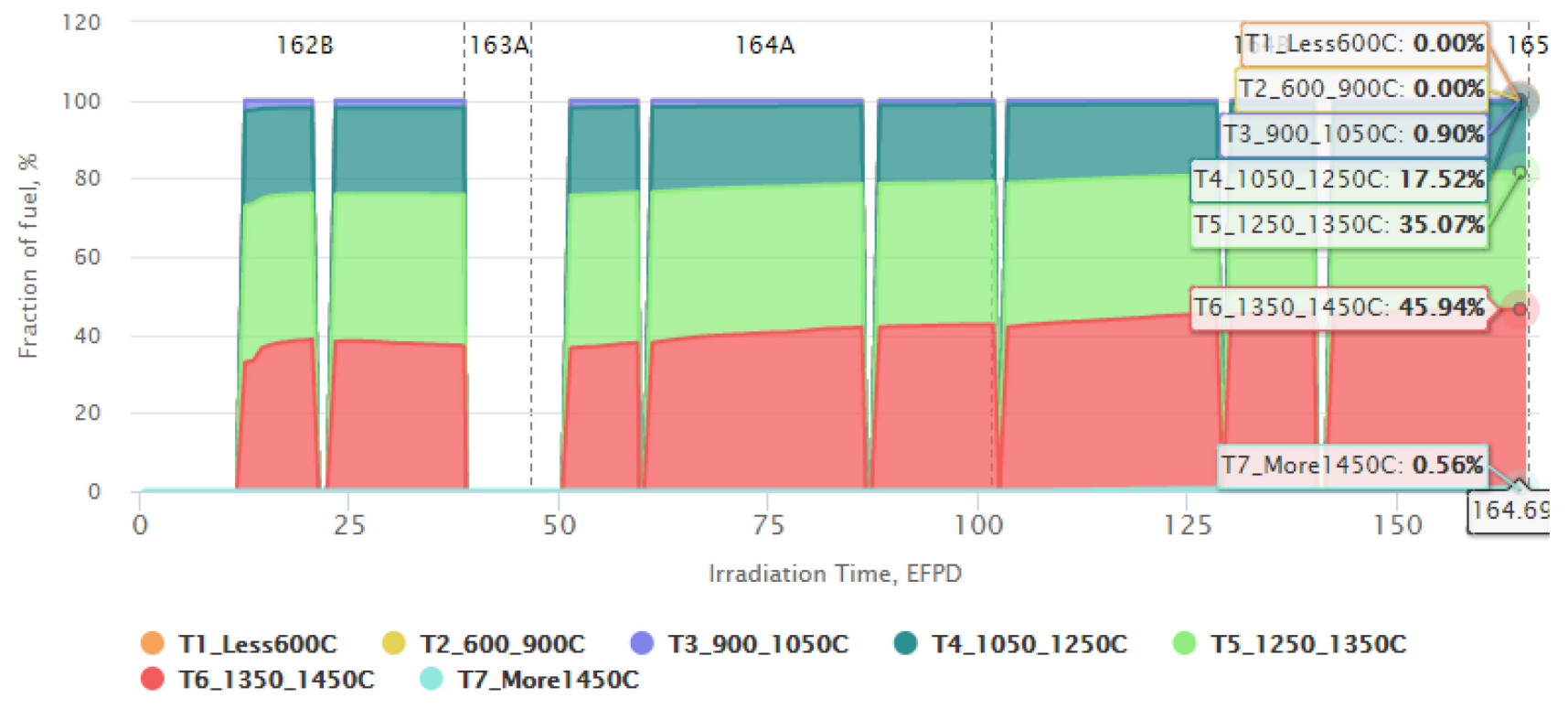

Figure 24. Time-averaged fuel-temperature fraction by range for AGR-7 capsule (only days when control TC reached setpoint temperature are included in the time averaging). 


\section{CONCLUSION}

The AGR-5/6/7 fuel test has been irradiated for five complete cycles, resulting in approximately 174 EFPDs (about one third of the 13-cycle schedule). At the end of Cycle 164B, burnup, fast fluence, and temperature histories may be summarized as follows:

- Capsule-average burnups ranged from 3.90\% FIMA in Capsule 5 to $7.48 \%$ FIMA in Capsule 2

- Capsule-average fast fluences ranged from $1.11 \times 10^{25} \mathrm{n} / \mathrm{m}^{2}$ in Capsule 5 to $2.26 \times 10^{25} \mathrm{n} / \mathrm{m}^{2}$ in Capsule 3

- Time-averaged volume-averaged fuel temperatures, on a capsule basis, at the end of the four completed irradiation cycles ranged from $705^{\circ} \mathrm{C}$ in Capsule 5 to $1255^{\circ} \mathrm{C}$ in Capsule 3 .

The gas line issues in Capsule 1 were rigorously mitigated to prevent crosstalk between capsule gas lines. As a result, fuel temperatures in all capsules are maintained within specified levels, and the loss of Capsule 1 fission-product release measurements is minimized.

The TCs perform consistently with previous AGR irradiation experiments: of the 54 installed TCs, 38 have failed before and during operation. Capsule 1, located on the bottom of the test train, has only one operational TC left.

Fission-gas isotope $\mathrm{R} / \mathrm{B}$ ratios reached values in the $10^{-8}-10^{-6}$ range during the competed irradiation period. Higher exposed kernel fraction and high temperature of fuel particles in Capsule 1 led to the maximum $\mathrm{R} / \mathrm{B}$ value of around $2 \times 10^{-6}$ for $\mathrm{Kr}-85 \mathrm{~m}$.

The results of this test will provide irradiation-performance data for the reference fuel manufactured at near commercial scale for a typical HTGR temperature range (AGR-5/6) as well as at temperatures beyond the normal range (AGR-7). Together with previous AGR data, AGR-5/6/7 data will form a link between fabrication processes, fuel-product properties, and irradiation performance. 


\section{REFERENCES}

Abaqus, 2014. Abaqus Version 6.14-2 documentation. Dassault Systèmes.

ASTM, 2014. Standard practice for testing graphite and boronated graphite materials for hightemperature gas-cooled nuclear reactor components. Designation C781-08, ASTM International, West Conshohocken, Pennsylvania.

Croff, A.G., 1983, "ORIGEN2: A Versatile Computer Code for Calculating the Nuclide Compositions and Characteristics of Nuclear Materials", Nuclear Technology, Vol. 62, pp. 335-352.

ECAR-2966, 2018, “Thermal Analysis of the AGR-5-6-7 Experiment,” Rev.5, October 23, 2018.

Folsom, C., C. Xing, C. Jensen, H. Ban, and D.W. Marshall, 2015. "Experimental measurement and numerical modeling of the effective thermal conductivity of TRISO fuel compacts," Journal of Nuclear Materials, 458, 198-205.

Gontard, R. and H. Nabielek, 1990. Performance Evaluation of Modern HTR TRISO Fuels. Report HTAIB-05/90, Forschungszentrum Jülich GmbH (FZJ).

Gonzo, E.E., 2002. "Estimating Correlations for the Effective Thermal Conductivity of Granular Materials," Chemical Engineering Journal, 90, 299-302.

Hawkes, G.L., J. W. Sterbentz, and M. Plummer, 2019, "Thermal Model Details and Description of the AGR-5/6/7 Experiment," ICAPP 2019 - International Congress on Advances in Nuclear Power Plants, France, Juan-les-pins, May 12-15, 2019.

Hull, L.C., 2015, “Nuclear Data Management and Analysis System Plan”, PLN-2709 Rev. 4, March 12, 2015.

Kestin, J., K. Knierim, E.A. Mason, B. Najafi, S.T. Ro, and M. Waldman, 1984. "Equilibrium and Transport Properties of the Noble Gases and Their Mixtures at Low Density," Journal of Physical and Chemical Reference Data, 13, 229-303.

LANL, X-5 Monte Carlo Team, 2004, MCNP-A General Monte Carlo N-Particle Transport Code, Version 5, Volume I, LA-UR-03-1987, Los Alamos National Laboratory, April 24, 2003 (Revised 6/30/2004) and Volume II, LA-CP-0245, Los Alamos National Laboratory, April 24, 2003 (Revised $6 / 30 / 2004)$.

PLN-3636, 2018, “Technical Program Plan for INL Advanced Reactor Technologies Advanced Gas Reactor Fuel Development and Qualification Program,” Rev. 7, June 29, 2018.

PLN-5245, 2018, “AGR-5/6/7 Irradiation Experiment Test Plan,” Rev. 1, January 25, 2018.

Rohrbaugh, D. T., 2017, “AGC-2 Irradiated Material Properties Analysis. United States: N. p., 2017.” Web. doi:10.2172/1369362.

Scates, D. M., 2010, "Fission Product Monitoring and Release Data for the Advanced Gas Reactor 1 Experiment," Proceedings HTR 2010, Prague, Czech Republic, October 18-20, 2010, Paper 52.

Shibata T., Motokuni Eto, Eiji Kunimoto, Shusaku Shiozawa, Kazuhiro Sawa, Tatsuo Oku and Tadashi Maruyama, Draft of Standard for Graphite Core Components in High Temperature Gas-cooled Reactors, Japan Atomic Energy Agency Research 2009-042, Jan 2010.

SPC-1352, 2017, “AGR-5/6/7 Fuel Specification,” Rev. 8, March 9, 2017.

Sterbentz, J. W., "JMOCUP As-Run Daily Depletion Calculation for the AGR-3/4 Experiment in the ATR Northeast Flux Trap,” ECAR-2753, Rev. 1, Idaho National Laboratory, July 25, 2015. 
Sterbentz, J. W., 2017, "JMOCUP Physics Depletion Calculation for the Design of the AGR-5/6/7 TRISO Particle Experiment in ATR Northeast Flux Trap,” ECAR-2961, Rev.1, June 13, 2017.

Swank D., Lord J., Rohrbaugh D., and Windes W., AGC-2 Graphite Pre-irradiation Data Package. United States: N. p., 2010. Web. doi:10.2172/991897.

Windes W., W. D. Swank, D. Rohrbaugh, and J. Lord, 2013, AGC-2 Graphite Preirradiation Data Analysis Report. United States: N. p., 2013. Web. doi:10.2172/1097190.

Windes W., 2012, Data Report on Post-Irradiation Dimensional Change of AGC-1 Samples. United States: N. p., 2012., Appendix A, Web. doi:10.2172/1056006. 


\section{APPENDIX A}

\section{Compact Time-averaged Temperature, Burnup, and Fast neutron Fluence at the End of 164B}




\section{Appendix A}

\section{Compact Time-averaged Temperature, Burnup, and Fast neutron Fluence at the End of 164B}

Table 9. Compact time-averaged temperature, burnup, and fast neutron fluence at the end of 164B.

\begin{tabular}{|c|c|c|c|c|c|c|}
\hline Capsule & Compact & $\begin{array}{c}\text { Time- } \\
\text { averaged } \\
\text { Minimum } \\
\text { Temperature } \\
\left({ }^{\circ} \mathrm{C}\right) \\
\end{array}$ & $\begin{array}{l}\text { Time-Averaged } \\
\text { Volume- } \\
\text { averaged } \\
\text { Temperature } \\
\left({ }^{\circ} \mathrm{C}\right) \\
\end{array}$ & $\begin{array}{c}\text { Time- } \\
\text { Averaged } \\
\text { Peak } \\
\text { Temperature } \\
\left({ }^{\circ} \mathrm{C}\right) \\
\end{array}$ & $\begin{array}{c}\text { Burnup } \\
(\% \text { FIMA) }\end{array}$ & $\begin{array}{c}\text { Fast neutron } \\
\text { Fluence } \\
\left(10^{25} \mathrm{n} / \mathrm{m}^{2},\right. \\
\mathrm{E}>0.18 \mathrm{MeV})\end{array}$ \\
\hline Capsule 5 & $5-1-1$ & 483 & 667 & 764 & 4.43 & 1.40 \\
\hline Capsule 5 & $5-1-2$ & 483 & 667 & 763 & 4.43 & 1.39 \\
\hline Capsule 5 & $5-1-3$ & 486 & 672 & 770 & 4.44 & 1.45 \\
\hline Capsule 5 & $5-1-4$ & 487 & 672 & 769 & 4.45 & 1.45 \\
\hline Capsule 5 & $5-2-1$ & 660 & 737 & 786 & 4.27 & 1.29 \\
\hline Capsule 5 & $5-2-2$ & 659 & 737 & 785 & 4.27 & 1.29 \\
\hline Capsule 5 & $5-2-3$ & 664 & 743 & 793 & 4.27 & 1.34 \\
\hline Capsule 5 & $5-2-4$ & 664 & 742 & 792 & 4.28 & 1.34 \\
\hline Capsule 5 & $5-3-1$ & 679 & 747 & 789 & 4.04 & 1.17 \\
\hline Capsule 5 & $5-3-2$ & 678 & 746 & 789 & 4.04 & 1.17 \\
\hline Capsule 5 & $5-3-3$ & 684 & 754 & 798 & 4.07 & 1.21 \\
\hline Capsule 5 & $5-3-4$ & 684 & 753 & 798 & 4.07 & 1.21 \\
\hline Capsule 5 & $5-4-1$ & 693 & 751 & 789 & 3.79 & 1.04 \\
\hline Capsule 5 & $5-4-2$ & 692 & 751 & 790 & 3.77 & 1.03 \\
\hline Capsule 5 & $5-4-3$ & 700 & 761 & 800 & 3.88 & 1.07 \\
\hline Capsule 5 & $5-4-4$ & 700 & 761 & 800 & 3.88 & 1.08 \\
\hline Capsule 5 & $5-5-1$ & 632 & 708 & 769 & 3.50 & 0.89 \\
\hline Capsule 5 & $5-5-2$ & 631 & 708 & 769 & 3.50 & 0.89 \\
\hline Capsule 5 & $5-5-3$ & 641 & 719 & 781 & 3.62 & 0.92 \\
\hline Capsule 5 & $5-5-4$ & 641 & 719 & 782 & 3.63 & 0.93 \\
\hline Capsule 5 & $5-6-1$ & 452 & 595 & 688 & 3.14 & 0.73 \\
\hline Capsule 5 & $5-6-2$ & 451 & 594 & 687 & 3.14 & 0.73 \\
\hline Capsule 5 & $5-6-3$ & 457 & 603 & 698 & 3.29 & 0.75 \\
\hline Capsule 5 & $5-6-4$ & 458 & 604 & 699 & 3.30 & 0.76 \\
\hline \multicolumn{2}{|c|}{ Capsule 5 compacts } & 451 & 705 & 800 & 3.90 & 1.11 \\
\hline Capsule 4 & 4-1-1 & 546 & 741 & 844 & 6.93 & 2.01 \\
\hline Capsule 4 & $4-1-2$ & 545 & 740 & 843 & 6.90 & 2.00 \\
\hline Capsule 4 & $4-1-3$ & 551 & 748 & 854 & 6.97 & 2.10 \\
\hline Capsule 4 & $4-1-4$ & 551 & 748 & 853 & 6.99 & 2.11 \\
\hline
\end{tabular}




\begin{tabular}{|c|c|c|c|c|c|c|}
\hline Capsule & Compact & $\begin{array}{c}\text { Time- } \\
\text { averaged } \\
\text { Minimum } \\
\text { Temperature } \\
\left({ }^{\circ} \mathrm{C}\right)\end{array}$ & $\begin{array}{c}\text { Time-Averaged } \\
\text { Volume- } \\
\text { averaged } \\
\text { Temperature } \\
\left({ }^{\circ} \mathrm{C}\right)\end{array}$ & $\begin{array}{c}\text { Time- } \\
\text { Averaged } \\
\text { Peak } \\
\text { Temperature } \\
\left({ }^{\circ} \mathrm{C}\right)\end{array}$ & $\begin{array}{c}\text { Burnup } \\
\text { (\% FIMA) }\end{array}$ & $\begin{array}{c}\text { Fast neutron } \\
\text { Fluence } \\
\left(10^{25} \mathrm{n} / \mathrm{m}^{2}\right. \\
\mathrm{E}>0.18 \mathrm{MeV})\end{array}$ \\
\hline Capsule 4 & $4-2-1$ & 738 & 829 & 889 & 6.94 & 1.98 \\
\hline Capsule 4 & $4-2-2$ & 738 & 829 & 889 & 6.92 & 1.97 \\
\hline Capsule 4 & $4-2-3$ & 746 & 839 & 900 & 6.99 & 2.06 \\
\hline Capsule 4 & $4-2-4$ & 745 & 838 & 899 & 7.01 & 2.07 \\
\hline Capsule 4 & 4-3-1 & 773 & 855 & 906 & 6.85 & 1.93 \\
\hline Capsule 4 & $4-3-2$ & 773 & 854 & 906 & 6.82 & 1.92 \\
\hline Capsule 4 & $4-3-3$ & 781 & 864 & 916 & 6.88 & 2.01 \\
\hline Capsule 4 & $4-3-4$ & 781 & 864 & 916 & 6.91 & 2.02 \\
\hline Capsule 4 & 4-4-1 & 793 & 866 & 910 & 6.66 & 1.87 \\
\hline Capsule 4 & $4-4-2$ & 792 & 866 & 909 & 6.64 & 1.86 \\
\hline Capsule 4 & $4-4-3$ & 799 & 874 & 918 & 6.69 & 1.95 \\
\hline Capsule 4 & $4-4-4$ & 800 & 875 & 920 & 6.72 & 1.96 \\
\hline Capsule 4 & $4-5-1$ & 755 & 842 & 901 & 6.42 & 1.80 \\
\hline Capsule 4 & $4-5-2$ & 753 & 840 & 900 & 6.40 & 1.79 \\
\hline Capsule 4 & $4-5-3$ & 759 & 848 & 908 & 6.44 & 1.87 \\
\hline Capsule 4 & $4-5-4$ & 760 & 849 & 910 & 6.47 & 1.88 \\
\hline Capsule 4 & 4-6-1 & 562 & 744 & 845 & 6.12 & 1.70 \\
\hline Capsule 4 & $4-6-2$ & 561 & 742 & 842 & 6.11 & 1.70 \\
\hline Capsule 4 & $4-6-3$ & 565 & 748 & 850 & 6.14 & 1.77 \\
\hline Capsule 4 & $4-6-4$ & 565 & 749 & 852 & 6.16 & 1.78 \\
\hline \multicolumn{2}{|c|}{ Capsule 4 compacts } & 545 & 816 & 920 & 6.67 & 1.92 \\
\hline Capsule 2 & $2-1-1$ & 538 & 723 & 824 & 6.78 & 1.91 \\
\hline Capsule 2 & $2-1-2$ & 538 & 723 & 825 & 6.78 & 1.91 \\
\hline Capsule 2 & $2-1-3$ & 542 & 731 & 835 & 6.83 & 2.00 \\
\hline Capsule 2 & $2-1-4$ & 541 & 729 & 832 & 6.83 & 2.00 \\
\hline Capsule 2 & $2-2-1$ & 721 & 814 & 880 & 7.14 & 1.98 \\
\hline Capsule 2 & $2-2-2$ & 721 & 815 & 880 & 7.14 & 1.97 \\
\hline Capsule 2 & $2-2-3$ & 728 & 824 & 891 & 7.20 & 2.07 \\
\hline Capsule 2 & $2-2-4$ & 726 & 821 & 888 & 7.20 & 2.06 \\
\hline Capsule 2 & $2-3-1$ & 762 & 845 & 899 & 7.37 & 2.03 \\
\hline Capsule 2 & $2-3-2$ & 762 & 846 & 899 & 7.36 & 2.02 \\
\hline Capsule 2 & $2-3-3$ & 770 & 856 & 911 & 7.43 & 2.12 \\
\hline Capsule 2 & $2-3-4$ & 768 & 854 & 908 & 7.43 & 2.12 \\
\hline Capsule 2 & $2-4-1$ & 761 & 848 & 899 & 7.52 & 2.07 \\
\hline Capsule 2 & $2-4-2$ & 761 & 849 & 900 & 7.53 & 2.06 \\
\hline
\end{tabular}




\begin{tabular}{|c|c|c|c|c|c|c|}
\hline Capsule & Compact & $\begin{array}{c}\text { Time- } \\
\text { averaged } \\
\text { Minimum } \\
\text { Temperature } \\
\left({ }^{\circ} \mathrm{C}\right)\end{array}$ & $\begin{array}{c}\text { Time-Averaged } \\
\text { Volume- } \\
\text { averaged } \\
\text { Temperature } \\
\left({ }^{\circ} \mathrm{C}\right)\end{array}$ & $\begin{array}{c}\text { Time- } \\
\text { Averaged } \\
\text { Peak } \\
\text { Temperature } \\
\left({ }^{\circ} \mathrm{C}\right)\end{array}$ & $\begin{array}{c}\text { Burnup } \\
\text { (\% FIMA) }\end{array}$ & $\begin{array}{c}\text { Fast neutron } \\
\text { Fluence } \\
\left(10^{25} \mathrm{n} / \mathrm{m}^{2}\right. \\
\mathrm{E}>0.18 \mathrm{MeV})\end{array}$ \\
\hline Capsule 2 & $2-4-3$ & 770 & 860 & 912 & 7.60 & 2.16 \\
\hline Capsule 2 & $2-4-4$ & 768 & 857 & 909 & 7.60 & 2.16 \\
\hline Capsule 2 & $2-5-1$ & 733 & 826 & 887 & 7.64 & 2.10 \\
\hline Capsule 2 & $2-5-2$ & 733 & 827 & 888 & 7.64 & 2.10 \\
\hline Capsule 2 & $2-5-3$ & 741 & 838 & 901 & 7.71 & 2.20 \\
\hline Capsule 2 & $2-5-4$ & 740 & 836 & 898 & 7.71 & 2.20 \\
\hline Capsule 2 & $2-6-1$ & 725 & 813 & 868 & 7.70 & 2.13 \\
\hline Capsule 2 & $2-6-2$ & 725 & 814 & 870 & 7.70 & 2.13 \\
\hline Capsule 2 & $2-6-3$ & 732 & 823 & 881 & 7.78 & 2.23 \\
\hline Capsule 2 & $2-6-4$ & 731 & 822 & 880 & 7.79 & 2.23 \\
\hline Capsule 2 & $2-7-1$ & 703 & 798 & 859 & 7.73 & 2.15 \\
\hline Capsule 2 & $2-7-2$ & 702 & 798 & 859 & 7.72 & 2.15 \\
\hline Capsule 2 & $2-7-3$ & 709 & 806 & 869 & 7.80 & 2.25 \\
\hline Capsule 2 & $2-7-4$ & 709 & 806 & 868 & 7.81 & 2.25 \\
\hline Capsule 2 & $2-8-1$ & 542 & 731 & 828 & 7.69 & 2.15 \\
\hline Capsule 2 & $2-8-2$ & 540 & 730 & 828 & 7.69 & 2.15 \\
\hline Capsule 2 & $2-8-3$ & 546 & 738 & 837 & 7.76 & 2.25 \\
\hline Capsule 2 & $2-8-4$ & 546 & 737 & 837 & 7.77 & 2.26 \\
\hline \multicolumn{2}{|c|}{ Capsule 2 compacts } & 538 & 804 & 912 & 7.48 & 2.11 \\
\hline Capsule 1 & $1-1-1$ & 607 & 762 & 870 & 2.54 & 0.70 \\
\hline Capsule 1 & $1-1-2$ & 607 & 761 & 870 & 2.50 & 0.69 \\
\hline Capsule 1 & $1-1-3$ & 612 & 765 & 874 & 2.58 & 0.71 \\
\hline Capsule 1 & $1-1-4$ & 614 & 772 & 883 & 2.74 & 0.73 \\
\hline Capsule 1 & $1-1-5$ & 622 & 781 & 893 & 2.92 & 0.75 \\
\hline Capsule 1 & $1-1-6$ & 624 & 787 & 901 & 3.02 & 0.76 \\
\hline Capsule 1 & $1-1-7$ & 625 & 787 & 901 & 3.02 & 0.75 \\
\hline Capsule 1 & $1-1-8$ & 623 & 782 & 895 & 2.88 & 0.74 \\
\hline Capsule 1 & $1-1-9$ & 615 & 774 & 887 & 2.75 & 0.73 \\
\hline Capsule 1 & $1-1-10$ & 613 & 767 & 877 & 2.59 & 0.71 \\
\hline Capsule 1 & $1-2-1$ & 747 & 880 & 982 & 3.39 & 0.89 \\
\hline Capsule 1 & $1-2-2$ & 746 & 879 & 980 & 3.41 & 0.89 \\
\hline Capsule 1 & $1-2-3$ & 749 & 883 & 985 & 3.45 & 0.91 \\
\hline Capsule 1 & $1-2-4$ & 756 & 891 & 995 & 3.51 & 0.93 \\
\hline Capsule 1 & $1-2-5$ & 764 & 901 & 1006 & 3.62 & 0.95 \\
\hline Capsule 1 & $1-2-6$ & 769 & 910 & 1015 & 3.70 & 0.96 \\
\hline
\end{tabular}




\begin{tabular}{|c|c|c|c|c|c|c|}
\hline Capsule & Compact & $\begin{array}{c}\text { Time- } \\
\text { averaged } \\
\text { Minimum } \\
\text { Temperature } \\
\left({ }^{\circ} \mathrm{C}\right)\end{array}$ & $\begin{array}{c}\text { Time-Averaged } \\
\text { Volume- } \\
\text { averaged } \\
\text { Temperature } \\
\left({ }^{\circ} \mathrm{C}\right)\end{array}$ & $\begin{array}{c}\text { Time- } \\
\text { Averaged } \\
\text { Peak } \\
\text { Temperature } \\
\left({ }^{\circ} \mathrm{C}\right)\end{array}$ & $\begin{array}{l}\text { Burnup } \\
\text { (\% FIMA) }\end{array}$ & $\begin{array}{c}\text { Fast neutron } \\
\text { Fluence } \\
\left(10^{25} \mathrm{n} / \mathrm{m}^{2}\right. \\
\mathrm{E}>0.18 \mathrm{MeV})\end{array}$ \\
\hline Capsule 1 & $1-2-7$ & 770 & 911 & 1017 & 3.70 & 0.96 \\
\hline Capsule 1 & $1-2-8$ & 766 & 905 & 1010 & 3.63 & 0.95 \\
\hline Capsule 1 & $1-2-9$ & 758 & 897 & 1002 & 3.53 & 0.93 \\
\hline Capsule 1 & $1-2-10$ & 751 & 887 & 990 & 3.44 & 0.91 \\
\hline Capsule 1 & $1-3-1$ & 824 & 966 & 1068 & 3.82 & 1.07 \\
\hline Capsule 1 & $1-3-2$ & 823 & 965 & 1066 & 3.83 & 1.07 \\
\hline Capsule 1 & $1-3-3$ & 826 & 969 & 1070 & 3.85 & 1.08 \\
\hline Capsule 1 & $1-3-4$ & 833 & 977 & 1080 & 3.92 & 1.11 \\
\hline Capsule 1 & $1-3-5$ & 842 & 988 & 1091 & 4.01 & 1.14 \\
\hline Capsule 1 & $1-3-6$ & 848 & 997 & 1101 & 4.07 & 1.15 \\
\hline Capsule 1 & $1-3-7$ & 849 & 999 & 1104 & 4.07 & 1.14 \\
\hline Capsule 1 & $1-3-8$ & 845 & 993 & 1098 & 4.01 & 1.13 \\
\hline Capsule 1 & $1-3-9$ & 836 & 984 & 1088 & 3.93 & 1.11 \\
\hline Capsule 1 & $1-3-10$ & 829 & 974 & 1077 & 3.87 & 1.09 \\
\hline Capsule 1 & $1-4-1$ & 881 & 1029 & 1125 & 4.14 & 1.23 \\
\hline Capsule 1 & $1-4-2$ & 880 & 1027 & 1123 & 4.15 & 1.23 \\
\hline Capsule 1 & $1-4-3$ & 882 & 1030 & 1126 & 4.17 & 1.24 \\
\hline Capsule 1 & $1-4-4$ & 889 & 1038 & 1133 & 4.21 & 1.28 \\
\hline Capsule 1 & $1-4-5$ & 897 & 1048 & 1143 & 4.29 & 1.30 \\
\hline Capsule 1 & $1-4-6$ & 904 & 1057 & 1152 & 4.36 & 1.31 \\
\hline Capsule 1 & $1-4-7$ & 905 & 1060 & 1155 & 4.36 & 1.31 \\
\hline Capsule 1 & $1-4-8$ & 901 & 1055 & 1151 & 4.30 & 1.30 \\
\hline Capsule 1 & $1-4-9$ & 893 & 1046 & 1143 & 4.22 & 1.28 \\
\hline Capsule 1 & $1-4-10$ & 885 & 1036 & 1133 & 4.18 & 1.25 \\
\hline Capsule 1 & $1-5-1$ & 901 & 1056 & 1147 & 4.43 & 1.37 \\
\hline Capsule 1 & $1-5-2$ & 900 & 1055 & 1145 & 4.43 & 1.37 \\
\hline Capsule 1 & $1-5-3$ & 902 & 1057 & 1147 & 4.44 & 1.39 \\
\hline Capsule 1 & $1-5-4$ & 904 & 1062 & 1151 & 4.45 & 1.42 \\
\hline Capsule 1 & $1-5-5$ & 909 & 1069 & 1159 & 4.50 & 1.45 \\
\hline Capsule 1 & $1-5-6$ & 914 & 1077 & 1167 & 4.55 & 1.46 \\
\hline Capsule 1 & $1-5-7$ & 915 & 1080 & 1169 & 4.55 & 1.45 \\
\hline Capsule 1 & $1-5-8$ & 913 & 1076 & 1166 & 4.50 & 1.44 \\
\hline Capsule 1 & $1-5-9$ & 909 & 1070 & 1161 & 4.47 & 1.42 \\
\hline Capsule 1 & $1-5-10$ & 905 & 1063 & 1154 & 4.46 & 1.39 \\
\hline Capsule 1 & $1-6-1$ & 902 & 1070 & 1177 & 4.69 & 1.50 \\
\hline
\end{tabular}




\begin{tabular}{|c|c|c|c|c|c|c|}
\hline Capsule & Compact & $\begin{array}{c}\text { Time- } \\
\text { averaged } \\
\text { Minimum } \\
\text { Temperature } \\
\left({ }^{\circ} \mathrm{C}\right)\end{array}$ & $\begin{array}{c}\text { Time-Averaged } \\
\text { Volume- } \\
\text { averaged } \\
\text { Temperature } \\
\left({ }^{\circ} \mathrm{C}\right)\end{array}$ & $\begin{array}{c}\text { Time- } \\
\text { Averaged } \\
\text { Peak } \\
\text { Temperature } \\
\left({ }^{\circ} \mathrm{C}\right)\end{array}$ & $\begin{array}{l}\text { Burnup } \\
\text { (\% FIMA) }\end{array}$ & $\begin{array}{c}\text { Fast neutron } \\
\text { Fluence } \\
\left(10^{25} \mathrm{n} / \mathrm{m}^{2}\right. \\
\mathrm{E}>0.18 \mathrm{MeV})\end{array}$ \\
\hline Capsule 1 & $1-6-2$ & 901 & 1069 & 1176 & 4.69 & 1.50 \\
\hline Capsule 1 & $1-6-3$ & 902 & 1070 & 1177 & 4.69 & 1.52 \\
\hline Capsule 1 & $1-6-4$ & 904 & 1074 & 1181 & 4.68 & 1.55 \\
\hline Capsule 1 & $1-6-5$ & 909 & 1081 & 1188 & 4.71 & 1.58 \\
\hline Capsule 1 & $1-6-6$ & 913 & 1087 & 1194 & 4.76 & 1.58 \\
\hline Capsule 1 & $1-6-7$ & 915 & 1088 & 1195 & 4.76 & 1.59 \\
\hline Capsule 1 & $1-6-8$ & 912 & 1086 & 1193 & 4.72 & 1.58 \\
\hline Capsule 1 & $1-6-9$ & 909 & 1082 & 1189 & 4.70 & 1.55 \\
\hline Capsule 1 & $1-6-10$ & 905 & 1076 & 1183 & 4.71 & 1.52 \\
\hline Capsule 1 & $1-7-1$ & 918 & 1099 & 1207 & 4.93 & 1.61 \\
\hline Capsule 1 & $1-7-2$ & 917 & 1098 & 1207 & 4.93 & 1.61 \\
\hline Capsule 1 & $1-7-3$ & 918 & 1099 & 1209 & 4.93 & 1.64 \\
\hline Capsule 1 & $1-7-4$ & 920 & 1102 & 1213 & 4.92 & 1.67 \\
\hline Capsule 1 & $1-7-5$ & 924 & 1109 & 1218 & 4.94 & 1.70 \\
\hline Capsule 1 & $1-7-6$ & 928 & 1113 & 1222 & 5.00 & 1.71 \\
\hline Capsule 1 & $1-7-7$ & 929 & 1114 & 1223 & 4.99 & 1.70 \\
\hline Capsule 1 & $1-7-8$ & 927 & 1113 & 1221 & 4.95 & 1.69 \\
\hline Capsule 1 & $1-7-9$ & 924 & 1109 & 1217 & 4.93 & 1.67 \\
\hline Capsule 1 & $1-7-10$ & 920 & 1103 & 1211 & 4.94 & 1.64 \\
\hline Capsule 1 & $1-8-1$ & 912 & 1103 & 1209 & 5.15 & 1.71 \\
\hline Capsule 1 & $1-8-2$ & 912 & 1105 & 1210 & 5.14 & 1.71 \\
\hline Capsule 1 & $1-8-3$ & 913 & 1107 & 1213 & 5.15 & 1.73 \\
\hline Capsule 1 & $1-8-4$ & 915 & 1109 & 1216 & 5.13 & 1.77 \\
\hline Capsule 1 & $1-8-5$ & 918 & 1113 & 1220 & 5.16 & 1.80 \\
\hline Capsule 1 & $1-8-6$ & 921 & 1116 & 1224 & 5.21 & 1.81 \\
\hline Capsule 1 & $1-8-7$ & 921 & 1116 & 1224 & 5.20 & 1.80 \\
\hline Capsule 1 & $1-8-8$ & 919 & 1114 & 1222 & 5.17 & 1.79 \\
\hline Capsule 1 & $1-8-9$ & 916 & 1111 & 1218 & 5.15 & 1.77 \\
\hline Capsule 1 & $1-8-10$ & 914 & 1106 & 1213 & 5.16 & 1.73 \\
\hline Capsule 1 & $1-9-1$ & 643 & 961 & 1163 & 5.43 & 1.77 \\
\hline Capsule 1 & $1-9-2$ & 644 & 962 & 1165 & 5.44 & 1.77 \\
\hline Capsule 1 & $1-9-3$ & 644 & 964 & 1168 & 5.46 & 1.80 \\
\hline Capsule 1 & $1-9-4$ & 646 & 966 & 1170 & 5.43 & 1.83 \\
\hline Capsule 1 & $1-9-5$ & 646 & 969 & 1174 & 5.47 & 1.86 \\
\hline Capsule 1 & $1-9-6$ & 650 & 971 & 1176 & 5.54 & 1.87 \\
\hline
\end{tabular}




\begin{tabular}{|c|c|c|c|c|c|c|}
\hline Capsule & Compact & $\begin{array}{c}\text { Time- } \\
\text { averaged } \\
\text { Minimum } \\
\text { Temperature } \\
\left({ }^{\circ} \mathrm{C}\right)\end{array}$ & $\begin{array}{l}\text { Time-Averaged } \\
\text { Volume- } \\
\text { averaged } \\
\text { Temperature } \\
\left({ }^{\circ} \mathrm{C}\right)\end{array}$ & $\begin{array}{c}\text { Time- } \\
\text { Averaged } \\
\text { Peak } \\
\text { Temperature } \\
\left({ }^{\circ} \mathrm{C}\right)\end{array}$ & $\begin{array}{l}\text { Burnup } \\
\text { (\% FIMA) }\end{array}$ & $\begin{array}{c}\text { Fast neutron } \\
\text { Fluence } \\
\left(10^{25} \mathrm{n} / \mathrm{m}^{2}\right. \\
\mathrm{E}>0.18 \mathrm{MeV})\end{array}$ \\
\hline Capsule 1 & $1-9-7$ & 649 & 971 & 1177 & 5.51 & 1.87 \\
\hline Capsule 1 & $1-9-8$ & 648 & 970 & 1175 & 5.49 & 1.86 \\
\hline Capsule 1 & $1-9-9$ & 646 & 966 & 1171 & 5.45 & 1.83 \\
\hline Capsule 1 & $1-9-10$ & 645 & 963 & 1166 & 5.46 & 1.80 \\
\hline \multicolumn{2}{|c|}{ Capsule 1 compacts } & 607 & 1002 & 1224 & 4.36 & 1.36 \\
\hline \multicolumn{2}{|c|}{ All AGR-5/6 compacts } & 451 & 897 & 1224 & 5.21 & 1.55 \\
\hline Capsule 3 & $3-1-1$ & 934 & 1127 & 1267 & 6.72 & 2.22 \\
\hline Capsule 3 & $3-1-2$ & 934 & 1128 & 1268 & 6.76 & 2.27 \\
\hline Capsule 3 & $3-1-3$ & 935 & 1129 & 1268 & 6.77 & 2.27 \\
\hline Capsule 3 & $3-2-1$ & 1136 & 1259 & 1348 & 7.32 & 2.25 \\
\hline Capsule 3 & $3-2-2$ & 1138 & 1260 & 1349 & 7.37 & 2.30 \\
\hline Capsule 3 & $3-2-3$ & 1139 & 1261 & 1348 & 7.38 & 2.30 \\
\hline Capsule 3 & $3-3-1$ & 1198 & 1300 & 1369 & 7.50 & 2.25 \\
\hline Capsule 3 & $3-3-2$ & 1200 & 1301 & 1370 & 7.55 & 2.31 \\
\hline Capsule 3 & $3-3-3$ & 1201 & 1301 & 1369 & 7.58 & 2.31 \\
\hline Capsule 3 & $3-4-1$ & 1210 & 1307 & 1372 & 7.55 & 2.25 \\
\hline Capsule 3 & $3-4-2$ & 1212 & 1308 & 1372 & 7.60 & 2.31 \\
\hline Capsule 3 & $3-4-3$ & 1213 & 1308 & 1372 & 7.62 & 2.31 \\
\hline Capsule 3 & $3-5-1$ & 1203 & 1302 & 1370 & 7.54 & 2.24 \\
\hline Capsule 3 & $3-5-2$ & 1206 & 1304 & 1371 & 7.59 & 2.30 \\
\hline Capsule 3 & $3-5-3$ & 1206 & 1304 & 1371 & 7.60 & 2.30 \\
\hline Capsule 3 & $3-6-1$ & 1196 & 1305 & 1379 & 7.45 & 2.23 \\
\hline Capsule 3 & $3-6-2$ & 1198 & 1307 & 1380 & 7.49 & 2.28 \\
\hline Capsule 3 & $3-6-3$ & 1201 & 1308 & 1381 & 7.52 & 2.28 \\
\hline Capsule 3 & $3-7-1$ & 1147 & 1284 & 1376 & 7.26 & 2.20 \\
\hline Capsule 3 & $3-7-2$ & 1148 & 1284 & 1376 & 7.30 & 2.25 \\
\hline Capsule 3 & $3-7-3$ & 1149 & 1286 & 1377 & 7.32 & 2.26 \\
\hline Capsule 3 & $3-8-1$ & 933 & 1153 & 1306 & 6.80 & 2.16 \\
\hline Capsule 3 & $3-8-2$ & 934 & 1153 & 1306 & 6.85 & 2.20 \\
\hline Capsule 3 & $3-8-3$ & 934 & 1153 & 1307 & 6.86 & 2.21 \\
\hline \multicolumn{2}{|c|}{ All AGR-7 compacts } & 933 & 1255 & 1381 & 7.30 & 2.26 \\
\hline
\end{tabular}

